\title{
Testosterone treatment improves metabolic syndrome-induced adipose tissue derangements
}

\author{
Elena Maneschi ${ }^{1, *}$, Annamaria Morelli ${ }^{2}{ }^{*}$, Sandra Filippi ${ }^{3}$, Ilaria Cellai ${ }^{1}$, Paolo Comeglio ${ }^{1}$, \\ Benedetta Mazzanti ${ }^{4}$, Tommaso Mello ${ }^{5}$, Alessandra Calcagno ${ }^{6}$, Erica Sarchielli ${ }^{2}$, Linda Vignozzi ${ }^{1}$, \\ Farid Saad7, Roberto Vettor ${ }^{6}$, Gabriella B Vannelli' ${ }^{2}$ and Mario Maggi ${ }^{1}$ \\ ${ }^{1}$ Sexual Medicine and Andrology Unit, Department of Clinical Physiopathology, ${ }^{2}$ Department of Anatomy, Histology and Forensic Medicine, \\ ${ }^{3}$ Interdepartmental Laboratory of Functional and Cellular Pharmacology of Reproduction, Departments of Pharmacology and Clinical Physiopathology, \\ ${ }^{4}$ Department of Hematology, Azienda Ospedaliera Universitaria Careggi (OUC) and ${ }^{5}$ Gastroenterology Unit, Department of Clinical Physiopathology, \\ University of Florence, Viale Pieraccini, 6, Florence 50139, Italy \\ ${ }^{6}$ Department of Medical and Surgical Sciences, Internal Medicine, University of Padua, Padua, Italy \\ ${ }^{7}$ Scientific Affairs Men's Healthcare, Bayer Pharma AG, Berlin, Germany \\ (Correspondence should be addressed to M Maggi; Email: m.maggi@dfc.unifi.it) \\ *(E Maneschi and A Morelli contributed equally to this work.)
}

\begin{abstract}
We recently demonstrated that testosterone dosing ameliorated the metabolic profile and reduced visceral adipose tissue (VAT) in a high-fat diet (HFD)-induced rabbit model of metabolic syndrome (MetS). We studied the effects of HFD and in vivo testosterone dosing on VAT function and the adipogenic capacity of rabbit preadipocytes isolated from VAT of regular diet (RD), HFD, and testosterone-treated HFD rabbits. VAT was studied by immunohistochemistry, western blot, and RT-PCR. Isolated rPADs were exposed to adipocyte differentiating mixture (DIM) to evaluate adipogenic potential. Adipocyte size was significantly increased in HFD VAT compared with RD, indicating adipocyte dysfunction, which was normalized by testosterone dosing. Accordingly, perilipin, an anti-lipolytic protein, was significantly increased in HFD VAT, when compared with other groups. HFD VAT was hypoxic, while testosterone dosing normalized VAT oxygenation. In VAT, androgen receptor expression was
\end{abstract}

positively associated with mRNA expression of GLUT4 (SLC2A4) (insulin-regulated glucose transporter) and STAMP2 (STEAP4) (androgen-dependent gene required for insulin signaling). In testosterone-treated HFD VAT, STAMP2 mRNA was significantly increased when compared with the other groups. Moreover, GLUT4 membrane translocation was significantly reduced in HFD VAT, compared with RD, and increased by testosterone. In DIM-exposed preadipocytes from HFD, triglyceride accumulation, adipocyte-specific genes, insulin-stimulated triglyceride synthesis, glucose uptake, and GLUT4 membrane translocation were reduced compared with preadipocytes from RD and normalized by in vivo testosterone dosing. In conclusion, testosterone dosing in a MetS animal model positively affects VAT functions. This could reflect the ability of testosterone in restoring insulin sensitivity in VAT, thus counteracting metabolic alterations.

Journal of Endocrinology (2012) 215, 347-362

\section{Introduction}

The increased prevalence of excessive visceral obesity is closely associated with the rising incidence of cardiovascular diseases (CVD) and type 2 diabetes mellitus. The clustering of cardiovascular risk factors in visceral obesity is often referred to as metabolic syndrome (MetS), which has been recognized to be a complication of adipose tissue dysfunction. It is well known that the main biological function of adipose tissue is to manage lipid storage providing both long-term and shortterm regulation and delivery of stored lipids in response to the peripheral energy need. Adipose tissue dysfunction starts when in the face of a nutritional overload there is a failure to accommodate all nutrients. This results in leakage of nutrients that accumulate in other organs such as liver and muscle. This inappropriate accumulation negatively impacts on the normal metabolic response of these organs (Després \& Lemieux 2006). How adipose tissue becomes dysfunctional is still unknown. Besides the excessive visceral deposition, several pathogenetic mechanisms are implicated, including brown to white fat transdifferentiation, mitochondrial damage and decreased mitochondrial biogenesis, an increased adipose cell size, a decreased insulin sensitivity of fat cells, and the failure of their storage function with the consequent peripheral lipotoxicity (Virtue \& Vidal-Puig 2010), macrophage infiltration, and inflammation along with qualitative and/or 
quantitative changes in adipokine production (Vettor et al. 2005), alteration in the angiogenetic process, and fibrosis development. Recently, stem cell abnormalities have also been described with alteration of the adipogenic process within adipose tissue or as an abnormal adipogenetic differentiation of stem cells residing in other organs (Aguiari et al. 2008, Vettor et al. 2009). The resulting metabolic consequences include abdominal obesity, insulin resistance, and atherogenic dyslipidemia along with a pro-thrombotic, inflammatory profile that defines the MetS.

MetS is often associated with testosterone deficiency in males (Laaksonen et al. 2003, Kapoor et al. 2005). A recent meta-analysis of the available cross-sectional studies on the association between MetS and hypogonadism found that patients with MetS had significantly lower testosterone plasma levels (about $3 \mathrm{nmol} / \mathrm{l}$ ), in comparison with agematched subjects (Corona et al. 2011a). In particular, androgen deficiency in men is associated with insulin resistance and obesity and testosterone treatment of hypogonadal patients improves insulin sensitivity and reduces fat mass (Corona et al. 2011a). Despite this evidence, the pathogenetic link and the clinical significance of MetSassociated male hypogonadism have not been completely clarified (Corona et al. 2011b). Epidemiological studies showed that MetS could predict the development of male hypogonadism (Niskanen et al. 2004, Esposito et al. 2008), which in turn may be a risk factor for MetS and CVD (Stellato et al. 2000, Oh et al. 2002, Corona et al. 2006, Kupelian et al. 2006, Rosano et al. 2007). Elevated waist circumference and hypertriglyceridemia resulted in the most important MetS determinants of hypogonadism (Corona et al. 2009). Thus, accumulation of visceral adipose tissue (VAT) may be regarded as the pathogenetic event linking these two conditions, even if the cause-effect relationship remains to be elucidated.

The precise role of androgens in regulating metabolism and body fat in males has been investigated in several animal studies, with the most important lesson being that derived from androgen receptor (AR) knockout (ARKO) mice (Yanase et al. 2008). The results from ARKO models revealed that AR plays an important role in male metabolism, by affecting the energy balance and lipolysis (Sato et al. 2003, Fan et al. 2005). A negative effect of AR activation on visceral adiposity has been clearly demonstrated in ARKO mice (Yanase et al. 2008). Accordingly, in vitro studies demonstrated that androgens inhibit adipogenic differentiation of mouse or human preadipocytes through an AR-mediated pathway (Singh et al. 2006, Gupta et al. 2008). By contrast, studies on the relationship between the androgen-AR system and insulin sensitivity produced conflicting results, showing both negative (Sato et al. 2003, Fan et al. 2005) and positive (Lin et al. 2005) effects.

Recently, we developed a non-genomic animal model of MetS, by exposing rabbits to a high-fat diet (HFD). Such a model essentially recapitulates the human MetS phenotype (hypertension, hyperglycemia, dyslipidemia, visceral fat accumulation, and reduced glucose tolerance), including a condition of hypogonadotropic hypogonadism (Filippi et al. 2009). Interestingly, testosterone dosing in MetS rabbits not only drastically prevented the HFD-induced VAT expansion but also reduced fasting glucose and improved glucose tolerance (Filippi et al. 2009, Vignozzi et al. 2011, 2012, Morelli et al. 2012a,b). Using this HFD-induced MetS model, the aim of this study is to investigate the role played by testosterone in adipose tissue dysfunction in this experimental MetS condition. Along with the evaluation of both morphological and functional VAT features, the study is focused on analyzing the adipogenic capacity of VAT preadipocytes, isolated from the MetS model, treated or not in vivo with testosterone. In particular, the ability of preadipocytes in responding to insulin is investigated in terms of triglyceride synthesis and lipid droplet formation, mRNA expression of adipogenesis-specific genes, as well as glucose uptake and glucose transporter 4 (GLUT4) membrane localization. Hence, this rabbit model responded well to the scope of the study aimed at analyzing adipose tissue function, given the sufficient amount of visceral fat to enable different experimental procedures (whole tissue analysis, isolation of fresh cell cultures of preadipocytes sufficient to perform several in vitro experiments at passage one). On the other hand, the main cons of using rabbits is the unfeasibility of procedures (i.e. microcomputed tomography (micro-CT) imaging) to measure body fat distribution.

\section{Materials and Methods}

\section{MetS rabbit model}

A rabbit model of MetS has been obtained in male New Zealand White rabbits (Charles River, Calco, Lecco, Italy), exposing them to a HFD, as described previously (Filippi et al. 2009). Animals were randomly numbered and assigned to different groups: untreated group $(n=35)$ fed a regular diet (RD) or treated group $(n=51)$ fed a HFD $(0 \cdot 5 \%$ cholesterol and $4 \%$ peanut oil) for 12 weeks. A subset of HFD rabbits $(n=19)$ was treated with i.m. injection of testosterone (30 mg/kg, weekly for 12 weeks). Blood samples were obtained from the animals via marginal ear vein at time 0 (baseline) and at week 12 in all groups. Mean arterial pressure and oral glucose tolerance test (OGTT) were measured, at the time of killing, as described previously (Filippi et al. 2009). Afterward, the rabbits were killed by a lethal dose of pentobarbital. VAT was harvested from the different experimental groups and appropriately processed for the subsequent analyses and preadipocyte isolation. Biochemical and hormonal serum analyses were performed as described previously (Filippi et al. 2009, Morelli et al. 2012a,b, Vignozzi et al. 2012). Animal handling complied with the Institutional Animal Care and Use Committee of the University of Florence, Florence, Italy, in accordance with the Italian Ministerial Law \# 116/92. 
Histomorphometric analysis of VAT

VAT specimens from all rabbit groups were removed, weighted, and fixed in $4 \%$ formalin in PBS. Tissues were then processed routinely for paraffin embedding, and $3 \mu \mathrm{m}$-thick sections were prepared for histomorphometric analysis. For each VAT sample, three to five sections were cut along the length. Hematoxylin and eosin-stained sections were used for direct microscopic examination. Negative staining controls were used in order to evaluate and subtract background. The diameter of adipocytes was measured using the Nikon Microphot-FXA microscope, considering the adipocytes more regularly spherical and using the program ImageJ.

\section{Hypoxia detection and immunohistochemistry}

VAT oxygenation was analyzed using the bio-reductive drug pimonidazole hydrochloride (Hypoxyprobe-1, $60 \mathrm{mg} / \mathrm{kg}$ ), i.p. injected $1 \mathrm{~h}$ before killing, as described previously (Morelli et al. 2012a,b, Vignozzi et al. 2012). VAT samples were rapidly removed and fixed in 4\% neutral-buffered formalin, dehydrated, and embedded in paraffin. Hypoxic cells were then easily detected by immunohistochemistry with a MAB (Hypoxyprobe-1Mab1), following the manufacturer's instruction. Computer-assisted quantification of the hypoxyprobe positivity has been made after background subtraction using Adobe Photoshop 6.0 software (Adobe Systems).

\section{Preparation of total and membrane/cytosolic fractions for western blot analysis}

VAT samples were ground in liquid nitrogen and divided into two aliquots: one for total protein extraction and the other for membrane/cytosolic preparations. Membrane and cytosolic fractions were prepared using the ProteoExtract sub-cellular proteome extraction kit (Calbiochem-Merck KGaA, Darmstadt, Germany), according to the manufacturer's instructions. Protein extracts were quantified with the BCA reagent (Pierce, Rockford, IL, USA). Equal amounts of proteins $(15 \mu \mathrm{g})$ were loaded onto 10\% SDS-PAGE and then transferred onto PVDF membrane (ImmobiloneP, Millipore Corporation, Bedford, MA, USA). After blocking in TRIS buffer saline $(0 \cdot 1 \%$ Tween 20$)$ and $5 \%$ skimmed milk for $1 \mathrm{~h}$, membranes were incubated with primary antibodies (anti-GLUT4 (1:1000), Upstate Biotechnology, Lake Placid, NY, USA; anti-perilipin (1:1000), anti-pAKT (1:1000), anti-AKT (1:1000), and anti-STAT1 (1:1000), Santa Cruz Biotechnology, Inc.) overnight at $4{ }^{\circ} \mathrm{C}$ followed by respective secondary antibody. Densitometry analysis of band intensity was performed using Photoshop 5.5 software (Adobe Systems, Inc. Italia srl).

\section{Isolation and culture of rabbit preadipocytes ( $r P A D s$ )}

rPAD isolation was performed according to Zuk et al. (2001). Briefly, after dissection under sterile conditions, VAT samples were immediately placed in serum-free (SF) DMEM/F12 (Sigma-Aldrich) supplemented with $200 \mu \mathrm{g} / \mathrm{ml}$ streptomycin and $200 \mathrm{U} / \mathrm{ml}$ penicillin. Then, VAT samples were washed in PBS, minced, and digested with $1 \mathrm{mg} / \mathrm{ml}$ collagenase type 2 (Sigma-Aldrich) in PBS, in a shaking water bath at $37^{\circ} \mathrm{C}$ for $1 \mathrm{~h}$. Collagenase type 2 was inactivated with an equal volume of DMEM containing 10\% fetal bovine serum (FBS) and the pellet was collected by centrifugation at $2000 \mathrm{~g}$ for $10 \mathrm{~min}$ at room temperature (RT). The cellular pellet was treated with red blood cell lysis buffer $\left(155 \mathrm{mM} \mathrm{NH}_{4} \mathrm{Cl}, 10 \mathrm{mM}\right.$ $\mathrm{KHCO}_{3}$, and $0.1 \mathrm{mM}$ EDTA) for $10 \mathrm{~min}$ at $\mathrm{RT}$, then centrifuged, resuspended in DMEM/10\% FBS, and filtered through a $150 \mu \mathrm{m}$ mesh filter to remove debris. The filtrate was centrifuged as detailed earlier and the cellular pellet was plated onto $100 \mathrm{~mm}$ cell culture dishes in complete culture medium (DMEM containing 10\% FBS, $100 \mu \mathrm{g} / \mathrm{ml}$ streptomycin, $100 \mathrm{U} / \mathrm{ml}$ penicillin, $2 \mathrm{mM} \mathrm{L-glutamine,} \mathrm{and}$ $1 \mu \mathrm{g} / \mathrm{ml}$ amphotericin-B; Sigma-Aldrich). Cells were cultured at $37{ }^{\circ} \mathrm{C}$ in humidified atmosphere of $95 \%$ air $-5 \% \mathrm{CO}_{2}$. After $24 \mathrm{~h}$, non-adherent cells were removed, while adherent cells were washed twice with PBS and left to grow in complete medium. A sub-confluent ( $90 \%$ of cell culture dish) and homogeneous fibroblast-like cell population at passage 0 (P0) was obtained after 4-5 days of culture. Sub-confluent cells were trypsinized and plated onto cell culture dishes (P1). For all the experiments, only P1 culture was used, and the experiments were repeated using at least three different $\mathrm{rPAD}$ preparations for each experimental group.

\section{Flow cytometry analysis}

rPADs were analyzed by flow cytometry for the expression of the following conjugated MABs: CD34-PE, CD45-FITC, CD31-FITC, CD14-PE, CD90-PE, CD106-FITC (BD Pharmingen, San Diego, CA, USA), and CD105 PE (Ancell, Bayport, MN, USA), as described previously (Mazzanti et al. 2008). Briefly, cells were harvested in 0.25\% trypsin/EDTA and washed in Hank's Balanced Salt Solution (HBSS) containing 10\% FBS. After re-suspension in the flow cytometry buffer CellWASH (PBS, 2\% FBS, $0 \cdot 1 \%$ sodium azide; Becton Dickinson, Milan, Italy) at a concentration of $1.5 \times 10^{5}$ cells $/ 100 \mu \mathrm{l}$, cells were incubated with the specific antibodies for $20 \mathrm{~min}$. Aminoactinomycin D (7-AAD) was added to exclude dead cells from the analysis. At least $10^{4}$ cells were acquired from each sample on FACSCalibur instrument (Becton Dickinson) and analyzed using the CellQuest software. Data are expressed as percentage of marker-positive cells over total and are reported as the mean \pm s.D. of the mean of $n$ different rPAD preparations from each experimental group.

\section{In vitro adipogenic differentiation}

rPADs plated in six-well $\left(8 \times 10^{4}\right.$ cells/well $)$ or in 96 -well $\left(9 \times 10^{3}\right.$ cells/well) plates were cultured until confluence. Two days after reaching confluence (time 0 ), the cells were stimulated with differentiation mixture (DIM) containing 
$5 \mu \mathrm{g} / \mathrm{ml}$ insulin, $1 \mu \mathrm{M}$ dexamethasone, and $0.5 \mathrm{mM}$ 3-isobutyl-1-methylxanthine in 5\% stripped FBS (FBS S)-supplemented DMEM for 8 days (Student et al. 1980). The culture medium was replaced every $48 \mathrm{~h}$, and then cells were shifted to medium containing $10 \mathrm{~g} / \mathrm{ml}$ insulin for $48 \mathrm{~h}$. The absence of testosterone in the culture medium was verified by measuring the hormone concentration in aliquots of FBS S/DMEM. Some aliquots of FBS S/DMEM were measured after adding a known concentration of testosterone $(8 \mathrm{nM})$ as internal control: the total recovery of testosterone was $8 \cdot 65 \pm 0 \cdot 8 \mathrm{nM}$.

\section{Qualitative and quantitative estimation of triglyceride accumulation}

DIM-rPADs were stained with Oil Red $\mathrm{O}$ to detect qualitative accumulation of intracellular lipids (Halvorsen et al. 2001). Dishes were washed in PBS, and cells were fixed in $10 \%$ formalin for $1 \mathrm{~h}$ at RT, followed by staining with Oil Red $\mathrm{O}$ for $5 \mathrm{~min}$. Oil Red $\mathrm{O}$ was prepared by diluting a stock solution $(0 \cdot 3 \mathrm{~g}$ Oil Red $\mathrm{O}$ in $100 \mathrm{ml}$ isopropanol) with water (3:2) followed by filtration. After staining, plates were washed twice in water and photographed. Quantitative estimation of triglyceride accumulation was performed by Adipored Assay (Cambrex BioScience, Walkersville, MD, USA). Briefly, after incubation with DIM for 10 days, the medium was removed and each well carefully rinsed with $200 \mu \mathrm{l}$ PBS. Each well was then filled with $200 \mu \mathrm{l}$ PBS and $5 \mu \mathrm{l}$ di Adipored, incubated at RT for 10-15 min and immediately placed in the fluorimeter for fluorescence measurement (excitation at $485 \mathrm{~nm}$ and emission at $572 \mathrm{~nm}$ ). Triglyceride content was normalized on protein content and adipogenic ability was expressed as percentage change vs untreated cells.

DIM-treated rPADs, Adipored stained, were imaged immediately using a Leica DMI6000 microscope equipped with a DFC350FX camera. Images were acquired using the Leica N3 filter set and a Fluotar $20 \times 0.4$ NA long-working distance objective with correction collar. Adipored-positive cells, identified as those clearly showing lipid droplets staining, were counted using ImageJ software and expressed as percentage change compared with total cells.

\section{Confocal microscopy}

DIM-treated rPADs, Adipored stained, were imaged immediately using a Leica SP2-AOBS confocal microscope. Images were collected as $z$-stacks through a $63 \times 1.2 \mathrm{NA}$ waterimmersion objective, sampling according to the Nyquist criterion and taking care to minimize spherical aberration by adjusting the objective correction collar. Images were then deconvolved with Huygens Professional software (SVI, The Netherlands) using the Classic Maximum Likelihood Estimation (CMLE) algorithm and a theoretical Point Spread Function (PSF). Finally, deconvolved images were quantitatively analyzed using Volocity 5 software (PerkinElmer, Foster City, CA, USA) to measure the number and volume of lipid droplets.

\section{GLUT4 and SNAP23 immunolocalization}

DIM-treated rPADs were cultured for $24 \mathrm{~h}$ in SF DMEM and then incubated for $5 \mathrm{~min}$ with insulin $(100 \mathrm{nM})$. Then, cells were treated for 15 min with membrane marker wheat germ agglutinin, rhodamine conjugated (WGA, 1:250, Vector Laboratories, Burlingame, CA, USA) and fixed with $3.7 \%$ paraformaldehyde $(\mathrm{pH} 7 \cdot 4)$ for $10 \mathrm{~min}$. Immunostaining was performed using anti-GLUT4 (1:40; Abcam Ltd, Cambridge, UK), followed by goat anti-mouse Alexa Fluor 488 secondary antibody (A11001, 1:200; Molecular Probes), or anti-SNAP23

Table 1 Primer sequences for quantitative RT-PCR in rabbit samples

Genes

CD90

$D K K 1$

PPARG

CEBPA

FABP4

ADPN

LEPT

DGAT2

SREBP2

$L P L$

$H S L$

PPARA

GLUT4

SNAP23

SYNT5

VAMP4

VIM

CCND1

CCND3

$B A X$
Primer sequences $\left(5^{\prime}-3^{\prime}\right)$

F: TGACAGTCTTGCAGGTGTCC

R: ACGCTCGTGGTGTTCTCAT

F: GACATGCGGTGGACTCCTAT

R: CAGGGGAGTTCCATCAAGAA

F: TGGGGATGTCTCATAATGCCA

R: TTCCTGTCAAGATCGCCCTCG F: TGGACAAGAACAGCAACGAG R: TTGTCACTGGTCAGCTCCAG F: GGATGGAAAATCAACCACCA R: GTGGAAGTGACGCCTTTCAT F: ACCAGGACAAGAACGTGGAC R: GAAGGAAGCCAGTGGAGATG F: GGAAAGTCCAGGATGACACC R: TCCATTGTGGACAAGCTCAG F: TCCAGTGGGTCTTGTCCTTC R: CCAGCCAGGTGAAGTAGAGC F: GGCGGACAAGACACAATATCA R: GTCCCCATGACCAAGTCTTTCA F: GACATTGGGGAGTTGCTGAT R: TTTCTCCCTGGAGCAGAAGA F: AGAGCCСССТCTAGCTCAAC R: CAAAGATTCGTGCCTGGATT F: GGCCTGGCCTTCTAAACATA R: TTCTTGATGACCTGCACGAG F: CTTCGAGACAGCAGGGGTAG R: AGAAGCAGAGCCACGTTCAT F: AGAAGAAGGCATGGACCAGA R: CTGGCTGCTTAGACACCACA F: CATCCAGAGTCGAGCAGACA R: CGTCGATCCTCTGAATGGTT F: AAGTTCAAGCGCCACCTAAA R: CCACCTGATTCTGAACATGC F: TGCAGGAAGAGATTGCCTTT R: GAGGTCAGGCTTGGAAACAT F: GAAGGACATCCAGCCCTACA R: AGGAAGCGGTCCAGGTAGTT F: GAAGCTGCACTCAGGGAGAG R: GATGGCTGTGACATCTGTGG F: CCTTTTGCTTCAGGGTTTCA R: ATCCTCTGCAGCTCCATGTT

CD90, cluster of differentiation 90; DKK1, dickkopf 1; CEBPA, CCAAT enhancer binding protein $\alpha, P P A R G$, peroxisome proliferator-activated receptors-gamma; $F A B P 4$, fatty acid binding protein $4 ; A D P N$, adiponectin; $L E P T$, leptin; DGAT2, diacylglycerol O-acyltransferase 2; SREBP2, sterol regulatory element binding protein-2; $L P L$, lipoprotein lipase; $H S L$, hormonesensitive lipase; PPARA, peroxisome proliferator-activated receptors- $\alpha$; GLUT4, glucose transporter type 4; SNAP23, synaptosomal-associated protein 23; SYNT5, syntaxin 5; VAMP4, vesicle-associated membrane protein 4; VIM, vimentin; CCND1, cyclin D1; CCND3, cyclin D3; $B A X, \mathrm{BCl} 2$-associated $\mathrm{X}$ protein. 
(1:100; Santa Cruz Biotechnology), followed by mouse antigoat FITC conjugate secondary antibody (1:50; SigmaAldrich). GLUT4/WGA or SNAP23/WGA colocalization was detected with Leica SP2-AOBS confocal microscope and calculated using the COLOC plugin of Image software. Results are given for Pearson overlap algorithm.

\section{Glucose uptake}

Glucose uptake in rPADs was performed as described previously (Raimondi et al. 2004). After 10 days of exposure to DIM, rPADs were cultured for $24 \mathrm{~h}$ in SF DMEM. Insulindependent stimulation was evaluated after $30 \mathrm{~min}$ of exposure to increasing concentrations of insulin $(1,5,10$, and $50 \mathrm{nM})$ diluted in glucose-free Krebs phosphate buffer $(2.5 \mathrm{mmol}$ $\left.\mathrm{Ca}^{2+}, 1 \mathrm{mg} / \mathrm{ml} \mathrm{BSA}\right)$. At the end of the incubation, glucose uptake was started by adding $\left[{ }^{3} \mathrm{H}\right] 2$-deoxy-D-glucose $(16 \mu \mathrm{M}[1 \mu \mathrm{Ci} / \mu \mathrm{l}]$; ICN Pharmaceuticals, Costa Mesa, CA, USA) for $5 \mathrm{~min}$. Cells were then washed with PBS, lysed with $\mathrm{NaOH} 0.5 \mathrm{M}$, and radioactivity incorporated was measured by scintillation liquid using a B-counter (PerkinElmer). Data were normalized on protein content.

\section{RNA extraction and quantitative RT-PCR analysis}

Isolation of RNA from tissue and cells was performed as described previously (Morelli et al. 2012a,b). cDNA synthesis was carried out using the iScriptTM cDNA Synthesis Kit (Bio-Rad Laboratories). Quantitative RT-PCR (qRT-PCR) was performed using SsoFastTM EvaGreen Supermix (Bio-Rad Laboratories) as previously reported (Morelli et al. $2012 a, b)$. Specific primers for all the target genes were either previously reported (Filippi et al. 2009, Morelli et al. 2012a,b, Vignozzi et al. 2012) or reported in Table 1. The expression of $18 \mathrm{~S}$ ribosomal RNA subunit, quantified with a predeveloped assay (Applied Biosystems), was chosen as reference gene and used for relative quantitation of the target genes. Amplification and detection were performed with the MyiQTM2 Two-Color Real-Time PCR Detection System (Bio-Rad Laboratories).

\section{Statistical analysis}

Results are expressed as mean \pm S.D. or S.E.M. for $n$ experiments as specified. Statistical analysis was performed with one-way ANOVA test followed by Tukey-Kramer post hoc analysis in order to evaluate differences between groups and $P<0 \cdot 05$ was considered significant. Correlations were assessed using Spearman's method and statistical analysis was performed on Statistical Package for the Social Sciences (SPSS, Inc., Chicago, IL, USA) for Windows 15.0. Halfmaximal response effective concentration $\left(\mathrm{EC}_{50}\right)$ values and maximal effect $\left(E_{\max }\right)$ values were calculated using the computer program ALLFIT (De Lean et al. 1978).

Table 2 Metabolic and hormonal parameters in experimental rabbits. Results are reported as mean \pm s.D. of the mean

\begin{tabular}{|c|c|c|c|}
\hline & $\mathbf{R D}(n=35)$ & $\operatorname{HFD}(n=32)$ & HFD + testosterone $(n=19)$ \\
\hline \multicolumn{4}{|c|}{ Total body weight (g) } \\
\hline Baseline & $3211 \cdot 9 \pm 281 \cdot 6$ & $3211 \cdot 2 \pm 333 \cdot 7$ & $3175 \cdot 4 \pm 300$ \\
\hline Week 12 & $3938 \pm 242^{+}$ & $3668 \cdot 7 \pm 297^{+}$ & $3804 \cdot 5 \pm 266 \cdot 3^{+}$ \\
\hline \multicolumn{4}{|c|}{ Blood glucose (g/l) } \\
\hline Baseline & $1 \cdot 2 \pm 0 \cdot 2$ & $1 \cdot 3 \pm 0 \cdot 2$ & $1 \cdot 2 \pm 0 \cdot 2$ \\
\hline Week 12 & $1 \cdot 2 \pm 0 \cdot 2$ & $1 \cdot 9 \pm 0 \cdot 4^{\neq, \S}$ & $1 \cdot 4 \pm 0 \cdot 3^{*, \|}$ \\
\hline \multicolumn{4}{|l|}{ OGTT (iAUC) } \\
\hline Week 12 & $158 \cdot 2 \pm 33 \cdot 1$ & $226 \cdot 5 \pm 43^{\neq}$ & $177 \pm 25 \cdot 3^{\| \prime}$ \\
\hline \multicolumn{4}{|c|}{ Cholesterol (mg/dl) } \\
\hline Baseline & $38 \cdot 2 \pm 13 \cdot 6$ & $43 \cdot 9 \pm 13$ & $49 \cdot 5 \pm 13 \cdot 5$ \\
\hline Week 12 & $45 \cdot 3 \pm 19$ & $1398 \cdot 9 \pm 349 \cdot 5^{\neq, \S}$ & $1244 \cdot 6 \pm 228 \cdot 3^{\neq, \S}$ \\
\hline \multicolumn{4}{|c|}{ Triglycerides (mg/dl) } \\
\hline Baseline & $86 \cdot 1 \pm 26 \cdot 6$ & $85 \cdot 4 \pm 24$ & $91 \cdot 4 \pm 29$ \\
\hline Week 12 & $102 \cdot 7 \pm 29$ & $299 \cdot 8 \pm 156 \cdot 1^{\neq, \S}$ & $293 \cdot 1 \pm 115 \cdot 5^{\neq, \S}$ \\
\hline \multicolumn{4}{|l|}{$\mathrm{MAP}(\mathrm{mmHg})$} \\
\hline Week 12 & $92 \cdot 9 \pm 13$ & $134 \cdot 9 \pm 21 \cdot 6^{\S}$ & $113 \cdot 5 \pm 8 \cdot 5^{\S, \mathbb{9}}$ \\
\hline \multicolumn{4}{|c|}{ Testosterone $(\mathrm{nmol} / \mathrm{l})$} \\
\hline Baseline & $6 \cdot 2 \pm 8$ & $8 \cdot 7 \pm 10 \cdot 1$ & $4 \cdot 9 \pm 3 \cdot 05$ \\
\hline Week 12 & $6 \cdot 1 \pm 4 \cdot 4$ & $1 \cdot 5 \pm 1 \cdot 6^{\ddagger, \S}$ & $17 \cdot 6 \pm 12 \cdot 5^{\neq, \S \text {, }}$ \\
\hline \multicolumn{4}{|c|}{$17 \beta$-Estradiol $(\mathrm{pmol} / \mathrm{l})$} \\
\hline Baseline & $150 \cdot 5 \pm 43 \cdot 6$ & $146 \cdot 4 \pm 51$ & $140 \cdot 2 \pm 40 \cdot 3$ \\
\hline Week 12 & $168 \cdot 7 \pm 53 \cdot 6$ & $307 \cdot 6 \pm 104 \cdot 1^{\neq, \S}$ & $161 \cdot 9 \pm 46 \cdot 1^{\top}$ \\
\hline \multicolumn{4}{|c|}{ Seminal vesicles weight (mg) } \\
\hline Week 12 & $729 \cdot 4 \pm 207$ & $491 \cdot 7 \pm 142^{\S}$ & $1551 \cdot 5 . \pm 438^{\S, \pi}$ \\
\hline \multicolumn{4}{|l|}{ Testis weight (g) } \\
\hline Week 12 & $3 \cdot 5 \pm 0 \cdot 3$ & $3 \pm 0 \cdot 3^{\S}$ & $1 \cdot 7 \pm 0 \cdot 3^{\S, \pi}$ \\
\hline
\end{tabular}

iAUC, incremental area under the curve of glucose blood level during OGTT; MAP, mean arterial pressure. ${ }^{*} P<0 \cdot 05,{ }^{+} P<0 \cdot 01,{ }^{\ddagger} P<0 \cdot 001 \mathrm{vs}$ baseline; ${ }^{\S} P<0 \cdot 001$ vs RD week 12 ; $" P<0 \cdot 01,{ }^{\Uparrow} P<0 \cdot 001$ vs HFD week 12. 

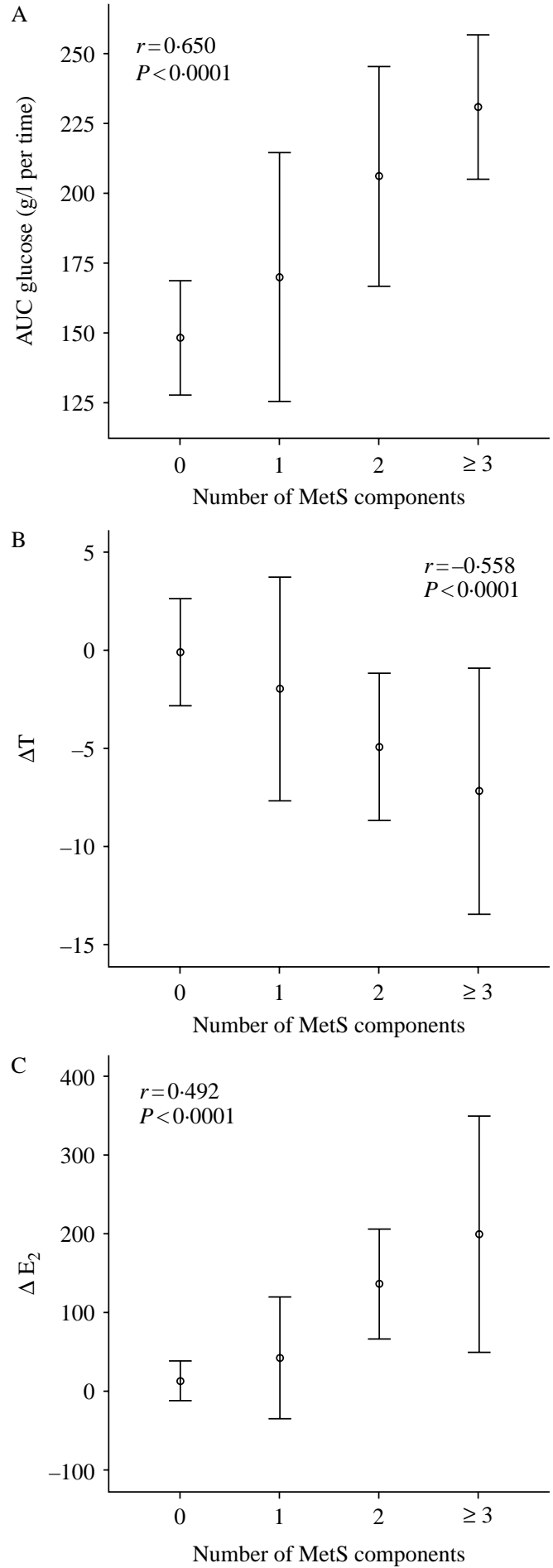

Figure 1 Relationship between the number of MetS components (abscissa) and the incremental area under the curve (AUC) of glucose during OGTT (A, $n=52$, ordinate), $\Delta \mathrm{T}$ (B, $n=59$, ordinate), or $\Delta \mathrm{E}_{2}(\mathrm{C}, n=61$, ordinate), as derived from univariate Spearman's regression analysis. The relative coefficient of correlation $(r)$ and level of significance $(P)$ are also reported.

\section{Results}

MetS features in experimental rabbits

Table 2 shows the main physical and biochemical characteristics of the different experimental groups. No statistical differences of total body weight after 12 weeks among groups have been found (Table 2). To evaluate the effects of MetS, we designed an algorithm taking into account the presence, as a dummy variable, of one or more of the following factors: hyperglycemia, high triglyceride, high cholesterol, increased blood pressure, and visceral fat accumulation. Cutoffs for each factor were derived by the mean \pm two S.D. of the analyzed parameter, as measured in RD rabbits. Positivity for three or more factors identifies MetS.

We found that glucose intolerance, as evaluated by the OGTT, increased as a function of the number of MetS components $(r=0.650 ; P<0.0001$; Fig. 1A). MetS rabbits were characterized by a sex steroid imbalance, including reduced testosterone and elevated estradiol $\left(\mathrm{E}_{2}\right)$ plasma levels, as previously published (Filippi et al. 2009, Morelli et al. 2012a,b, Vignozzi et al. 2012). Interestingly, $\Delta \mathrm{T}$ (testosterone at 12 weeks - testosterone at baseline) negatively $(r=-0.558$; $P<0 \cdot 0001)$ while $\Delta \mathrm{E}_{2}\left(\mathrm{E}_{2}\right.$ at 12 weeks $-\mathrm{E}_{2}$ at baseline $)$ positively $(r=0.492 ; P<0.0001)$ correlated with the number of MetS components (Fig. 1B and C respectively).

Significant associations were also found between $\Delta \mathrm{T}$ and/or $\Delta \mathrm{E}_{2}$ and the mRNA expression of several genes in VAT, as reported in Fig. 2 and Table 3. In particular, $\Delta \mathrm{T}$ positively, and $\Delta \mathrm{E}_{2}$ negatively, correlated with the glucose transporter GLUT4 $(r=0.430, P<0.0001$ and $r=-0.257, P<0.05$ respectively, Fig. $2 \mathrm{~A}$ and $\mathrm{B})$. By contrast, the insulin-sensitizing adipokine adiponectin $(A D P N(A D I P O Q))$ was highly testosterone sensitive $(r=0 \cdot 464, P<0 \cdot 0001$; Fig. $2 \mathrm{C})$, while the hypoxia marker CA9 was estrogen sensitive $(r=0 \cdot 454, P<0 \cdot 01$; Fig. 2D). Other genes involved in lipid turnover along with their relationship with sex steroid variation are summarized in Table 3. The expression of the apoptosis-related gene $B A X$ was not only upregulated by $\Delta \mathrm{T}(r=0 \cdot 335, P=0 \cdot 01$; Table 3$)$ but also tightly associated with the expression of $A R$ in VAT $(r=0 \cdot 375, P<0 \cdot 005$; Table 4).

We next analyzed other associations between $A R$ mRNA and the VAT expression of several genes involved in lipid turnover. As shown in Table 4, significant positive associations were found between $A R$ and genes regulating adipogenesis (PPARG, CEBPA, FABP4, PPARA, ADPN, and LEPT), glucose transport and insulin signaling (GLUT4, RHOA, $R O C K 2, V I M$, and $S T A M P 2)$, and lipid droplet formation (VAMP4, SYNT5, and SNAP23). By contrast, AR mRNA was negatively associated with the early-induced adipogenic gene, DKK1 (Table 4).

To further characterize the role of testosterone in MetSrelated VAT dysfunctions, we treated a subset of HFD rabbits with testosterone $(30 \mathrm{mg} / \mathrm{kg}$ per week) for 12 weeks. We found that testosterone dosing to HFD rabbits was able to not only restore plasma testosterone and $\mathrm{E}_{2}$ levels (Table 2) 

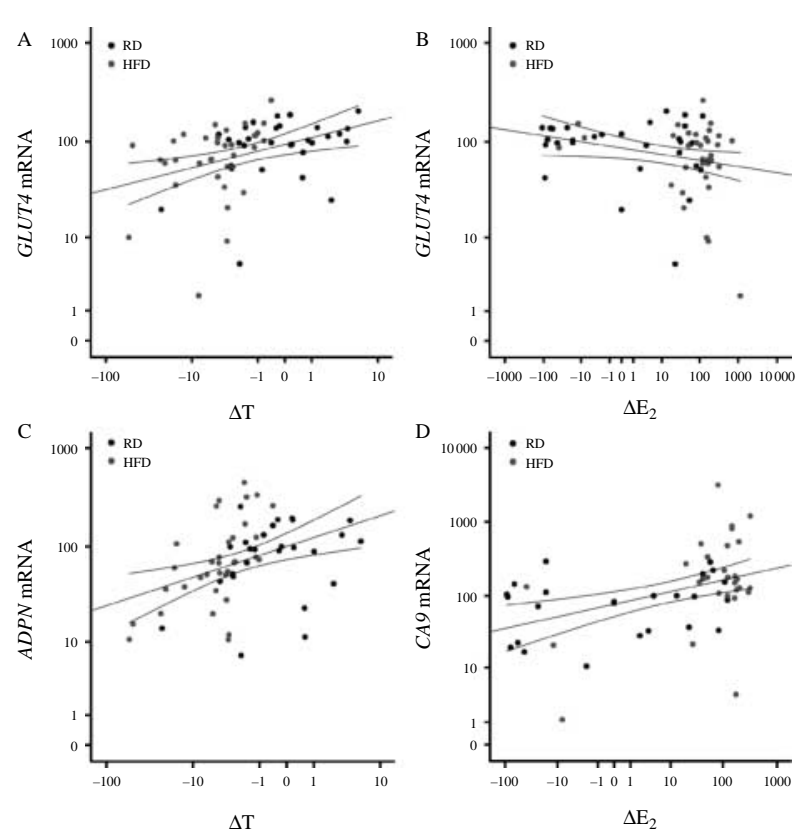

Figure 2 Relationship between GLUT4 mRNA (ordinate) and $\Delta T$ (A, abscissa) or $\Delta \mathrm{E}_{2}(\mathrm{~B}$, abscissa), as derived from univariate Spearman's regression analysis $(n=65)$. (C) Relationship between $A D P N$ mRNA (ordinate) and $\Delta \mathrm{T}$ (abscissa), as derived from univariate Spearman's regression analysis $(n=60)$. (D) Relationship between CA9 mRNA (ordinate) and $\Delta \mathrm{E}_{2}$ (abscissa), as derived from univariate Spearman's regression analysis $(n=54)$. The relative coefficient of correlation $(r)$ and level of significance $(P)$ are reported within the text. Solid lines indicate the $95 \%$ confidence interval of the regression line.

but also decrease the prevalence of MetS (from $82 \%$ in HFD to $18 \cdot 2 \%$ in $\mathrm{HFD}+$ testosterone, $P<0 \cdot 01$ ), by decreasing the number of components fulfilling MetS criteria $(\mathrm{HFD}=2 \cdot 54 \pm 0 \cdot 15$ vs HFD + testosterone $=1 \cdot 86 \pm 0 \cdot 18$, $P=0 \cdot 005)$. In particular, testosterone dosing dramatically reduced VAT weight $(\mathrm{HFD}=41 \cdot 51 \pm 2 \cdot 05$ vs $\mathrm{HFD}+\mathrm{T}=4 \cdot 37 \pm 0 \cdot 87$, $P<0 \cdot 0001$, Fig. 3A, B, C and D). Histomorphometric analysis evidenced that adipocyte size was significantly increased in HFD rabbits, compared with the RD group $(P<0 \cdot 05)$, and reduced by testosterone dosing $(P<0 \cdot 001 \mathrm{vs}$ RD and HFD; Fig. 3E, F, G and H). In addition, HFD VAT was hypoxic, as demonstrated by the significant increase of hypoxyprobe positivity $(P<0.0001$ vs RD; Fig. 3I, J, and L), while testosterone treatment normalized VAT oxygenation $(P<0.0001$ vs HFD; Fig. 3J, K and L).

Western blot analysis showed that the expression of the anti-lipolytic protein perilipin was significantly increased in VAT from HFD rabbits, compared with RD and testosterone-treated HFD groups $(P=0 \cdot 001$, Fig. 3M). In addition, mRNA expression of $S T A M P 2$, a gene induced by androgens and required for normal insulin signaling, was significantly increased in VAT from testosterone-treated HFD rabbits, when compared with RD and untreated HFD groups $(P<0 \cdot 02$; Fig. 4A).
To further investigate the effects of HFD and testosterone treatment on insulin signaling, we analyzed the intracellular localization of GLUT4 and the pAKT/AKT ratio in VAT protein extracts. Figure 4B shows that GLUT4 membrane translocation was significantly reduced in HFD compared with the RD group $(P=0 \cdot 02)$, while it was restored in VAT from testosterone-treated HFD rabbits. Similarly, HFD VAT showed a reduced $\mathrm{pAKT} / \mathrm{AKT}$ ratio compared with the RD group $(P=0 \cdot 03$; Fig. $4 \mathrm{C})$, that was normalized by testosterone $(P<0 \cdot 05$ vs HFD).

\section{Molecular and functional characterization of visceral adipocyte precursor cells from experimental rabbits}

To investigate the effects of HFD and in vivo testosterone treatment on VAT adipogenic capacity, we isolated rPADs from VAT of all experimental groups. Each cell preparation was characterized by flow cytometry for the expression of mesenchymal stem cell (MSC) markers and hematopoieticmonocytic contamination. The percentage of positive cells expressing MSC markers CD90, CD105, and CD106 was not statistically different among the different groups, as reported in Table 5. All rPADs were negative for endothelial (CD31), hemopoietic (CD34 and CD45), and monocytic (CD14) markers. Expression analysis by qRT-PCR showed that CD90 (THY1) was the most abundant gene in all rPADs, followed by the two adipocyte commitment markers $D K K 1$ and $F A B P 4$, without statistical differences among the groups (Table 5).

The adipogenic potential of rPADs was investigated by exposing in vitro cells to a DIM for 10 days. The qualitative estimation by Oil Red $\mathrm{O}$ staining of triglyceride accumulation showed an increase in lipid droplets in the cytosol of all rPAD groups when compared with untreated cells (Fig. 5A). Quantitative analysis by Adipored assay of triglyceride

Table 3 Association between $\Delta \mathrm{T}$ or $\Delta \mathrm{E}_{2}$ and mRNA expression lipogenic/lipolytic genes in VAT

\begin{tabular}{|c|c|c|c|c|}
\hline & \multicolumn{2}{|l|}{$\Delta \mathrm{T}$} & \multicolumn{2}{|l|}{$\Delta \mathrm{E}_{2}$} \\
\hline & $r$ & $P$ value & $r$ & $P$ value \\
\hline \multicolumn{5}{|c|}{ Lipogenic genes } \\
\hline PPARG & $0 \cdot 343$ & $0 \cdot 007$ & $-0 \cdot 178$ & $0 \cdot 178$ \\
\hline$A D P N$ & $0 \cdot 464$ & $<0 \cdot 0001$ & $-0 \cdot 239$ & $0 \cdot 071$ \\
\hline LEPT & $0 \cdot 414$ & $0 \cdot 001$ & $-0 \cdot 223$ & $0 \cdot 096$ \\
\hline DGAT2 & $0 \cdot 449$ & $0 \cdot 001$ & $-0 \cdot 425$ & $0 \cdot 002$ \\
\hline SREBP2 & $0 \cdot 474$ & $0 \cdot 003$ & $-0 \cdot 470$ & $0 \cdot 003$ \\
\hline STAR & $0 \cdot 390$ & $0 \cdot 025$ & -0.566 & $0 \cdot 001$ \\
\hline \multicolumn{5}{|c|}{ Lipolytic genes } \\
\hline$L P L$ & $0 \cdot 508$ & $<0 \cdot 0001$ & $-0 \cdot 332$ & $0 \cdot 011$ \\
\hline PPARA & $0 \cdot 275$ & $0 \cdot 032$ & $-0 \cdot 122$ & $0 \cdot 359$ \\
\hline$H S L$ & $0 \cdot 283$ & $0 \cdot 049$ & $-0 \cdot 482$ & $<0 \cdot 0001$ \\
\hline \multicolumn{5}{|c|}{ Apoptotic gene } \\
\hline$B A X$ & $0 \cdot 335$ & $0 \cdot 01$ & $-0 \cdot 189$ & $0 \cdot 155$ \\
\hline
\end{tabular}

Correlation coefficients $(r)$ and level of significance ( $P$ value) are derived from univariate analysis. 
Table 4 Association between $A R$ mRNA and VAT-specific genes

\begin{tabular}{|c|c|c|}
\hline & $r$ & $P$ value \\
\hline \multicolumn{3}{|c|}{ Adipogenesis } \\
\hline DKK1 & -0.372 & $0 \cdot 004$ \\
\hline PPARG & 0.560 & $<0 \cdot 0001$ \\
\hline CEBPA & $0 \cdot 620$ & $<0 \cdot 0001$ \\
\hline FABP4 & $0 \cdot 610$ & $<0 \cdot 0001$ \\
\hline$A D P N$ & $0 \cdot 281$ & $0 \cdot 033$ \\
\hline$\angle E P T$ & $0 \cdot 308$ & $0 \cdot 020$ \\
\hline PPARA & 0.572 & $<0.0001$ \\
\hline \multicolumn{3}{|c|}{ Glucose transport and insulin signaling } \\
\hline GLUT4 & $0 \cdot 291$ & $0 \cdot 026$ \\
\hline RHOA & $0 \cdot 354$ & $0 \cdot 007$ \\
\hline ROCK 2 & $0 \cdot 315$ & $0 \cdot 017$ \\
\hline STAMP2 & $0 \cdot 474$ & $<0 \cdot 0001$ \\
\hline VIM & $0 \cdot 571$ & $<0 \cdot 0001$ \\
\hline \multicolumn{3}{|c|}{ Lipid droplet formation } \\
\hline VAMP4 & $0 \cdot 535$ & $<0 \cdot 0001$ \\
\hline SYNT5 & $0 \cdot 359$ & $0 \cdot 010$ \\
\hline SNAP23 & $0 \cdot 476$ & $<0 \cdot 0001$ \\
\hline \multicolumn{3}{|l|}{ Apoptosis } \\
\hline$B A X$ & $0 \cdot 375$ & $0 \cdot 004$ \\
\hline
\end{tabular}

Correlation coefficients $(r)$ and level of significance ( $P$ value) are derived from univariate analysis.

content revealed a significant increase in Adipored positivity in DIM-exposed rPADs from each group when compared with the untreated counterpart, although to a different extent (Fig. 5B). In fact, while in rPADs from RD, DIM induced a $534 \%$ increase over the basal level $(P<0 \cdot 0001)$, the increase in rPADs from HFD was modest (66\%), although still statistically significant $(P<0 \cdot 05)$. In vivo testosterone dosing partially restores responsiveness to DIM in rPAD from HFD (262\% increase, $P<0 \cdot 0001)$. Adipored positivity in DIM-exposed rPADs from HFD was statistically different when compared with all other groups $(P<0 \cdot 01$, Fig. $5 \mathrm{~B})$.

The percentage of Adipored-positive cells, calculated by fluorescence microscopy inspection after DIM exposure, was significantly lower in rPADs from HFD than in rPADs from RD $(P<0.01$; Fig. 6A, B and $G)$ and rPAD from testosterone-treated HFD $(P<0 \cdot 01$; Fig. $6 \mathrm{~B}, \mathrm{C}$ and $\mathrm{G})$. By confocal microscopy, we analyzed the lipid droplet content within the single cell. As shown in Fig. 6, lipid droplets from DIM-treated rPADs from HFD showed both a reduction in the average number (Fig. $6 \mathrm{E}$ and $\mathrm{H} ; P<0 \cdot 05$ ) and an increase in the size (Fig. 6E and I; $P<0.0001$ ), when compared with those from DIM-treated rPADs from RD (Fig. 6D, H and I). Interestingly, both number and size of lipid droplets of DIM-treated rPAD from testosterone-treated HFD were comparable to RD levels (Fig. 6F, H and I).

The responsiveness of rPADs to DIM has also been investigated in terms of expression of adipocyte-related genes (PPARG, DKK1, FABP4, ADPN, and LEPT). As reported in Table 6 , in rPADs from RD, there was a significant induction of all the investigated genes after 10 days of exposure to DIM, when compared with the basal (time 0$)$ expression $(P<0 \cdot 01)$. In rPADs from HFD, DIM exposure was able to significantly induce FABP4 mRNA, without changing the expression of all the other genes investigated, which was significantly reduced $(P<0 \cdot 01$ vs the other groups). DIM-induced expression of all adipocyte-specific genes, with the exception of LEPT, was observed in rPAD from testosterone-treated HFD (Table 6). Similarly, cyclin D3 (CCND3) mRNA expression, which has been described to become predominant during adipogenic differentiation (Hishida et al. 2008), was significantly induced in all DIM-treated rPADs, with the exception of rPAD from HFD (Table 6). On the contrary, cyclin D1 (CCND1) mRNA, which is usually unregulated during the period of mitotic expansion that precedes adipogenic differentiation (Hishida et al. 2008), was significantly increased only in DIM-treated rPADs from HFD and not in the other groups $(P<0 \cdot 05$, Table 6$)$.

To better investigate whether the reduced ability of rPADs from HFD in responding to DIM was due to an impaired sensitivity to insulin, we analyzed the lipid content in DIM-treated rPADs after exposure to increasing concentrations of insulin. As shown in Fig. 7A, the percentage of triglyceride accumulation in response to insulin increased in a dose-dependent manner, with the same $\mathrm{EC}_{50}$ for all rPADs (shared $\mathrm{EC}_{50}=99 \pm 84 \mathrm{nM}$ ). However, the maximal effect of insulin was significantly reduced in rPADs from HFD compared with RD and testosterone-treated HFD, which was not different $\left(E_{\max }=111 \cdot 8 \pm 4 \cdot 5\right.$ vs shared $\left.E_{\max }=140 \pm 11, P<0 \cdot 01\right)$. Insulin sensitivity of rPADs was then investigated in terms of glucose uptake induced by increasing concentrations of insulin. Although insulin dose dependently stimulated glucose uptake in all rPADs with the same $\mathrm{EC}_{50}$ (shared $\mathrm{EC}_{50}=3 \cdot 8 \pm 1.6 \mathrm{nM}$; Fig. $7 \mathrm{~B}$ ), the maximal effect was significantly reduced in rPADs from $\operatorname{HFD}\left(E_{\max }=111 \pm 12 \%\right)$ compared with the other rPADs (shared $E_{\max }=219 \pm 15 \%, P<0 \cdot 01$ ).

To determine the insulin-stimulated glucose transport vesicles trafficking in DIM-treated rPADs, we examined the GLUT4 and SNAP23 membrane localization after insulin stimulation (100 nM, 5 min). Using confocal microscopy and WGA a as membrane marker, we found that in rPADs from HFD, insulin stimulation was less effective in stimulating GLUT4 and SNAP23 membrane translocation $(8 \pm 0 \cdot 3$ and $19 \cdot 3 \pm 0.9 \% ; P<0.01$ respectively) when compared with RD $(26 \cdot 4 \pm 5 \cdot 7$ and $24 \cdot 2 \pm 0 \cdot 9 \%$ respectively, both $P<0 \cdot 01$; Fig. 8). GLUT4 and SNAP23 membrane translocation in rPADs from testosterone-treated rabbits was comparable to those from RD $(29 \cdot 2 \pm 0 \cdot 8$ and $27 \cdot 1 \pm 0 \cdot 9 \%$ respectively; Fig. 8).

\section{Discussion}

This study demonstrates that in a animal model of MetS (diet-induced), VAT is not only increased in mass but it is also dysfunctional, showing morphostructural alterations, along with an impaired insulin-stimulated adipogenic ability of the preadipocyte component. In vivo testosterone dosing to MetS 
A

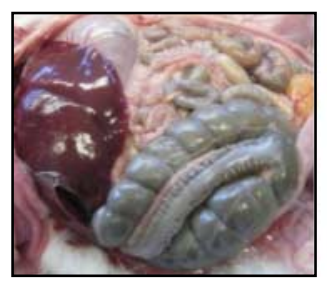

E

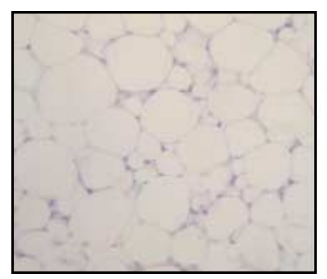

I

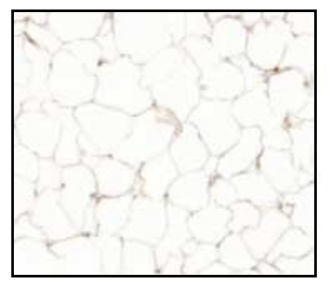

B

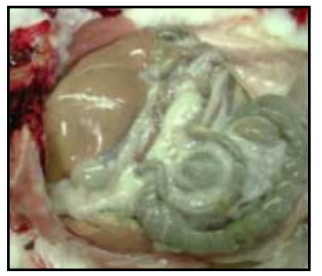

F

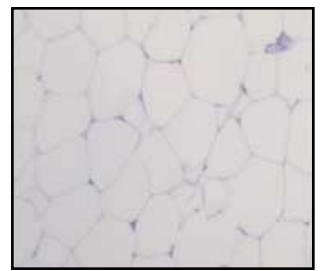

J

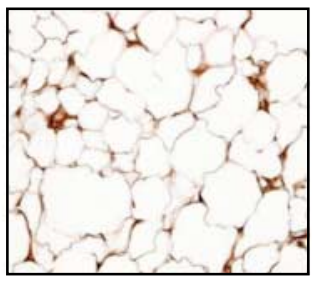

C

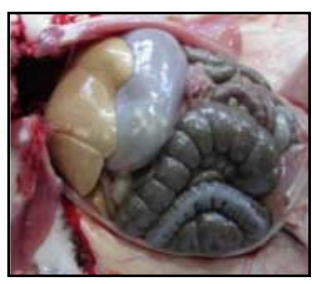

G

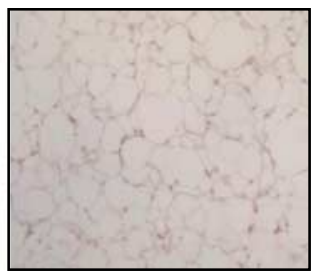

K

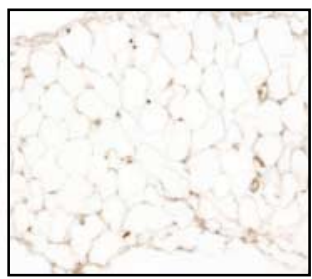

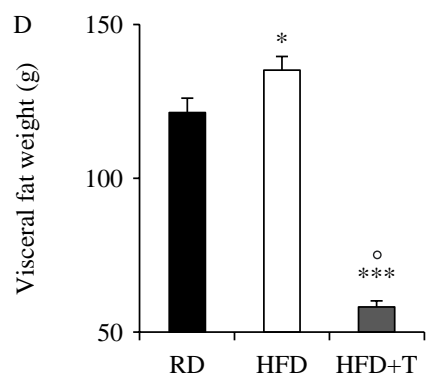

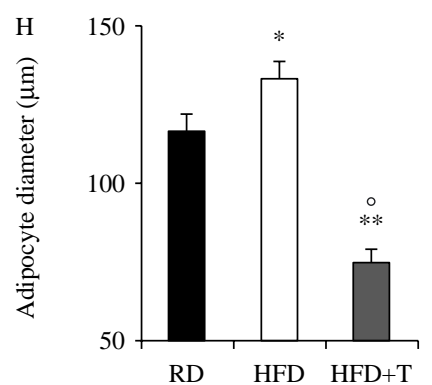

L

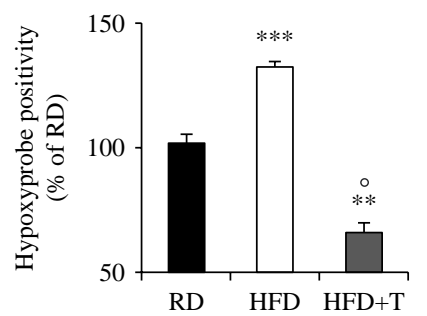

M

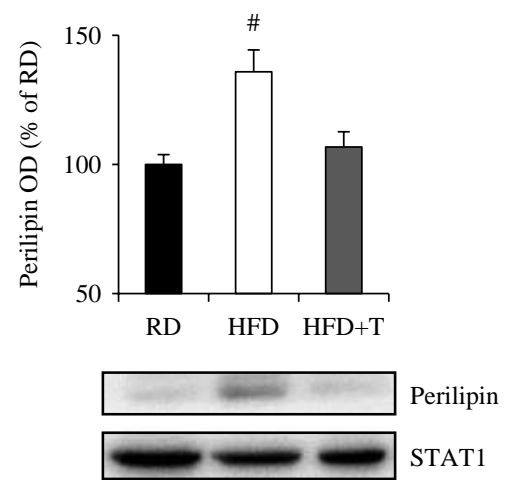

Figure 3 Effects of testosterone treatment on VAT weight, adipocyte size, and hypoxia in experimental rabbits. (A, B, and C) Pictures show fat accumulation at the visceral level within the intestinal loops. (D) VAT weight was significantly increased in HFD rabbits $(n=32)$, when compared with RD $(n=35)$ and testosterone-treated HFD rabbits (HFD+T; $n=19)$. (E, F and G) Representative images of hematoxylin/eosin-stained VAT sections showing different adipocyte size among experimental groups (magnification $20 \times$ ). $(\mathrm{H})$ Histomorphometric analysis of adipocyte diameter $(\mu \mathrm{m})$ in the different experimental groups $(n=3$ for each group). (I, J, K, L) Immunohistochemical staining of hypoxyprobe adducts in VAT sections. Hypoxyprobe adducts were revealed in hypoxic cells (PO2 $<10 \mathrm{mmHg}$ ) of VAT transverse sections by a MAB (magnification $12.5 \times$ ). Only scanty positive labeling is present in RD (I) and testosterone-treated HFD (K) VAT, while intense hypoxyprobe positivity is detected in HFD VAT (J). (L) Computer-assisted quantitative image analysis of three independent experiments ( $n=3$ for each group). RD optical density was taken as $100 \%$. (M) Protein expression of perilipin in VAT extracts from experimental rabbits. Representative immunoblots with anti-perilipin and anti-STAT1 primary antibodies and the corresponding graphical representation of optical density (OD) analysis of perilipin band intensity normalized over STAT1 ( $n=3$ for each group) are reported. Data are mean \pm S.E.M. expressed as percentage of RD values $* P<0 \cdot 05$; ${ }^{* *} P<0.001 ;{ }^{* *} P<0.0001$ vs $\mathrm{RD},{ }^{\circ} P<0.0001$ vs HFD and ${ }^{*} P=0.001$ vs all groups. Full color version of this figure available via http://dx.doi.org/10.1530/JOE-12-0333. 

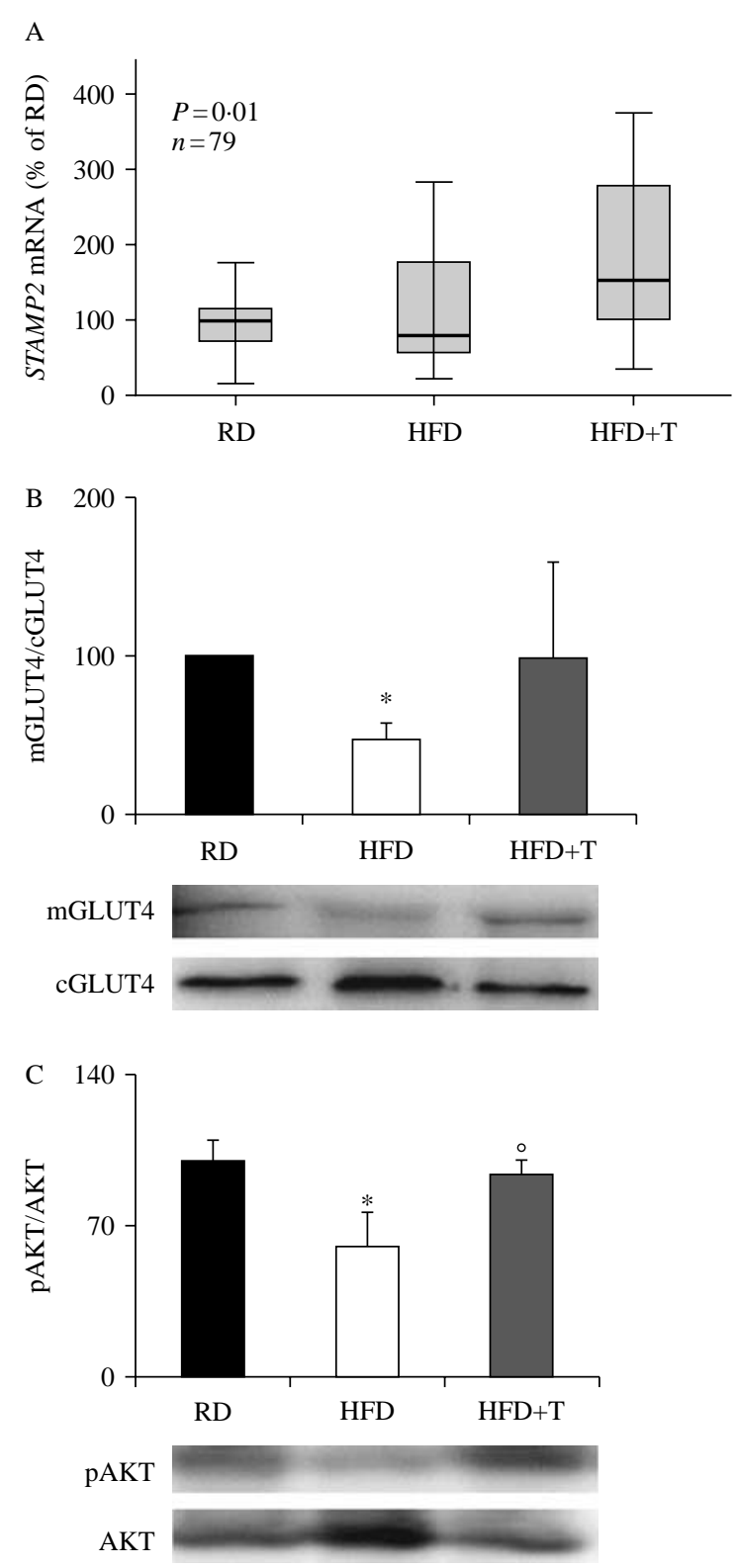

Figure 4 Analysis of the STAMP2 mRNA expression, GLUT4 membrane translocation, and PAKT/AKT ratio in VAT. (A) Quantitative analysis using real-time RT-PCR for STAMP2 mRNA expression in VAT extracts from all animal groups. Data are calculated according to the comparative cycle threshold method using 185 ribosomal RNA subunit as the reference gene for normalization and are expressed as percentage of RD values. (B) The lower panel shows the representative immunoblots with anti-GLUT4 primary antibody on membrane $(\mathrm{m})$ and cytosolic (c) fractions of VAT from RD, HFD, and testosteronetreated HFD rabbits. Bar graph shows optical density analysis of membrane/cytosol GLUT4 ratio expressed as mean \pm s.E.M. of at least three different samples from each group. (C) The lower panel shows the representative immunoblots with pAKT and AKT as primary antibodies on total protein extracts of VAT from RD, HFD, and testosterone-treated HFD rabbits. Bar graph shows optical density analysis of pAKT/AKT ratio expressed as mean \pm S.E.M. of at least three different samples from each group. ${ }^{*} P<0.05$ vs RD, ${ }^{\circ} P<0 \cdot 05$ vs HFD. animals was able to counteract all the HFD-induced VAT alterations, restoring preadipocyte maturation through a clear positive effect on their insulin sensitivity. Overall, these effects of testosterone on adipose tissue functions, along with the improvement of MetS factor (fasting glucose, glucose tolerance, and hypertension), indicate a crucial role played by androgens in metabolic control. Although several previous studies explored the effect of adding testosterone in vitro to differentiating preadipocytes (Singh et al. 2003, 2006, Gupta et al. 2008), this is the first report on a prolonged (3 months) in vivo testosterone dosing showing persistent effects in ex vivo VAT tissue cultures.

The association of MetS with an imbalance of sex steroid plasma levels (concomitant testosterone decrease and $\mathrm{E}_{2}$ increase) has been well established in humans (Corona et al. 2011a,b), as well as in the HFD-induced rabbit MetS model (Filippi et al. 2009). Interestingly, we found that androgenic decreased $(\Delta T)$ negatively, while estrogenic increased $\left(\Delta \mathrm{E}_{2}\right)$ positively, correlated with the number of MetS components. The existence of correlations between sex hormone levels and body fat distribution could also be envisaged but not demonstrated in this study because of the technical difficulties in applying to rabbits the micro-CT system used with small rodents (Quarta et al. 2010). Moreover, testosterone dosing in HFD rabbits improved insulin sensitivity (reduction of glycemia, improvement of glucose tolerance, and reduction of VAT). Accordingly, $\Delta \mathrm{T}$ was positively associated with VAT expression of GLUT4, and ADPN - two markers of insulin sensitivity - while $\Delta \mathrm{E}_{2}$ negatively associated with GLUT4 mRNA expression. $\Delta \mathrm{E}_{2}$ also positively associated with VAT expression of the hypoxia marker CA9. Hypoxia of adipose tissue represents a determinant mechanism for the dysregulation of tissue function (O'Rourke et al. 2011) and insulin resistance (Trayhurn et al. 2008). In obese mice, hypoxia is localized and is not systemic, due to hypoperfusion of the rapidly expanding fat mass (Hosogai et al. 2007, Ye et al. 2007). Accordingly, morphostructural analysis of VAT clearly shows that in MetS animals, the expanded tissue is hypertrophic, characterized not only by a reduced oxygenation but also by an increased adipose cell size. Several studies in the early 1970s have well established that, compared with small adipocytes, large adipocytes exhibit reduced insulin-stimulated glucose uptake (Salans \& Dougherty 1971, Smith 1971, Jacobsson \& Smith 1972, Olefsky 1976). Consistent with these findings, VAT from MetS rabbits showed a reduced membrane expression of GLUT4 (Huang \& Czech 2007) and a decreased AKT signaling activation, along with an increased expression of perilipin, the main anti-lipolytic protein coating the cytosolic surface of intracellular lipid droplets (Brasaemle 2007).

One of the most striking results of our study is that, besides counteracting the HFD-induced visceral fat mass expansion, testosterone dosing completely prevented all the MetS-related VAT alterations, reducing adipocyte size and hypoxia, as well as restoring membrane GLUT4, pAKT/AKT ratio, and perilipin expression. In addition, $\Delta \mathrm{T}$ positively correlated 
Table 5 Characterization of rPADs at passage 1 from each experimental group. (a) Cells were labeled with surface antibodies and analyzed by flow cytometry. Data are expressed as percentage of marker-positive cells and are reported as the mean \pm s.D. of $n$ different rPAD preparations from each experimental group. No statistically significant differences were found among groups. (b) Expression of $C D 90$ and pre-adipocyte markers by qRT-PCR in rPADs. Data are reported as the mean (s.D.) of $n$ different rPAD preparations from each experimental group. No statistically significant differences were found among groups

(a) Immunophenotype by flow cytometry

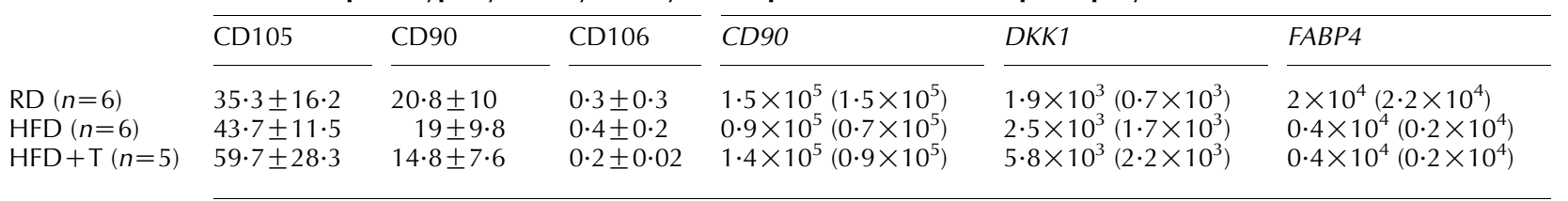

with the expression in VAT of several genes involved in lipid turnover, such as lipogenic (PPARG, DGAT2, SREBP2, and $S T A R$ ), adipose tissue-specific (LEPT and $A D P N)$, and lipolytic (LPL, PPARA, and HSL (LIPE)) genes. Interestingly, we also found that VAT expression of all these genes correlated with $\Delta \mathrm{E}_{2}$, but in a negative manner, thus further indicating the deleterious role played by the MetS-related sex steroid imbalance on adipose tissue function and metabolism. However, additional investigations, such as aromatase activity/expression analysis, that could help to clarify the differences in the correlations of the sex hormones have not been performed in this study.

The mechanisms through which testosterone regulates fat mass are poorly understood (Singh et al. 2003, 2006, Gupta et al. 2008). Testosterone inhibits adipocyte differentiation through the AR-mediated nuclear translocation of $\beta$-catenin and the subsequent activation of Wnt signaling (Rosen \& MacDougald 2006). When activated, Wnt signaling promotes differentiation of resident MSCs into myocytes and osteocytes, while suppressing their commitment toward the adipocyte lineage and terminal differentiation by inhibiting the expression of PPARG and CEBPA, the central regulators of adipogenesis (Christodoulides et al. 2006, 2009). In our study in VAT, mRNA expression of both PPARG and $C E B P A$ was tightly positively associated with $A R$ expression, which also positively correlated with several genes exploring not only adipogenesis (FABP4, ADPN, and LEPT) but also other VAT-specific functions, such as lipid droplet formation,

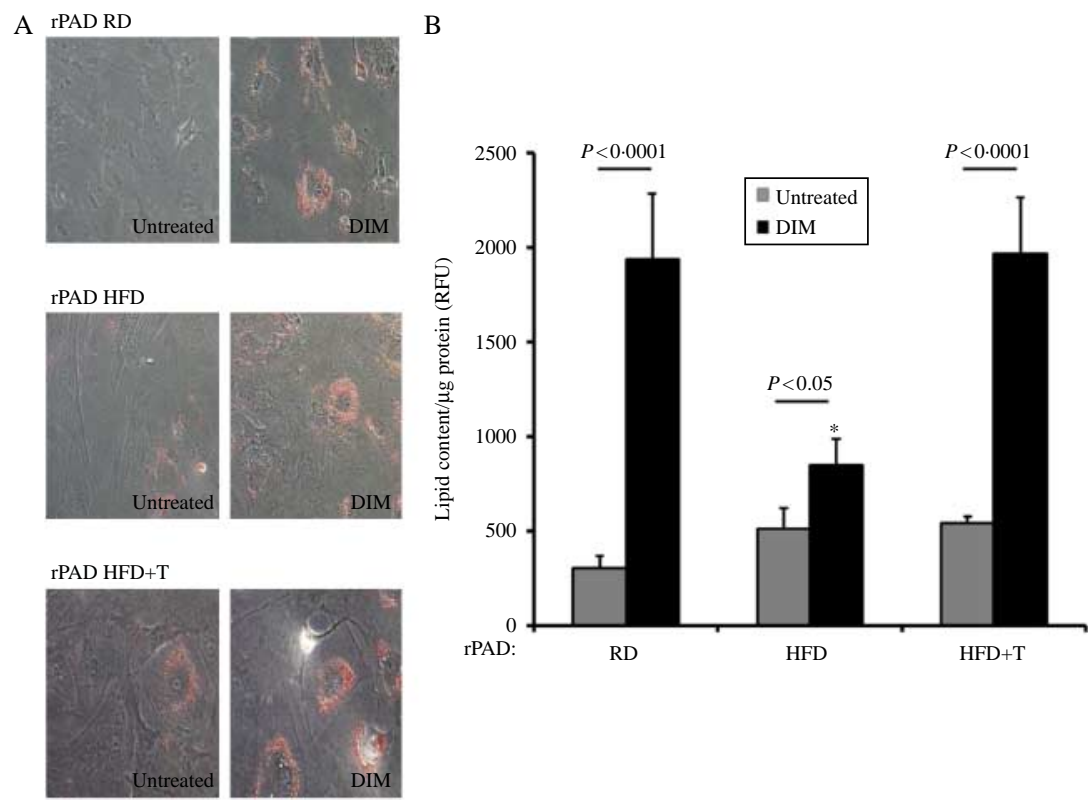

Figure 5 The adipogenic response of rPADs to DIM. (A) Lipid content in untreated (left panels) and DIM-exposed (right panels) rPADs from each experimental group, as evaluated by Oil Red O staining. (B) Quantitative assessment of lipid content in untreated (gray bars) and DIM-exposed (black bars) rPADs from each experimental group, as evaluated by Adipored assay. Results are expressed as relative fluorescence unit (RFU) per microgram of protein and are reported as mean \pm S.E.M. ( $n=5$ for each group). $* P<0 \cdot 01$ vs all other DIM-rPAD. Full color version of this figure available via http://dx.doi.org/10.1530/JOE-12-0333. 


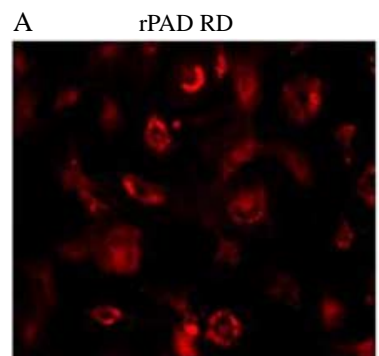

$\mathrm{D}$

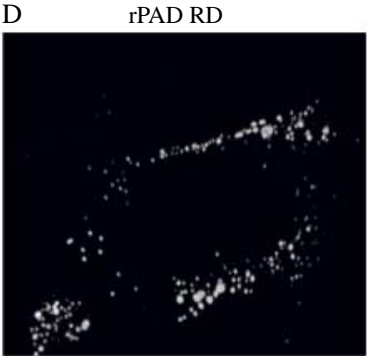

G

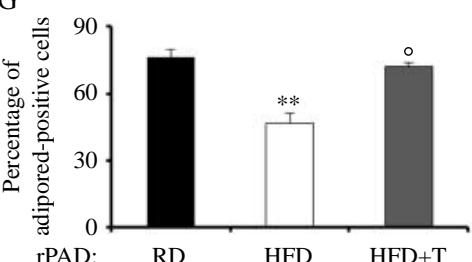

B

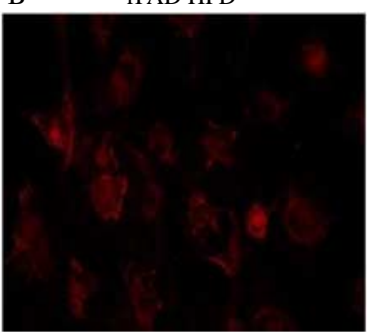

E

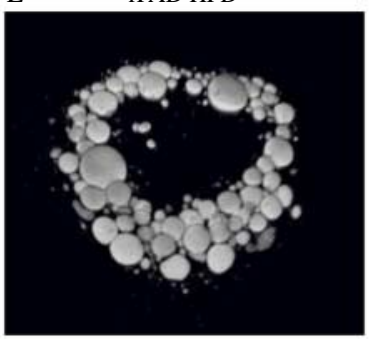

$\mathrm{H}$

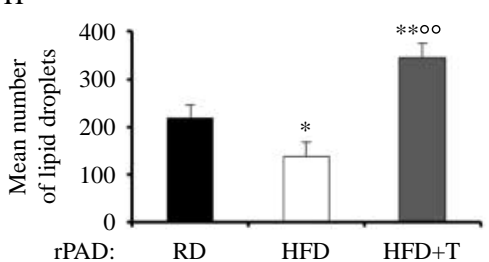

$\mathrm{C}$

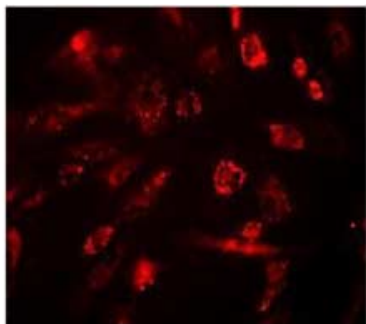

$\mathrm{F}$

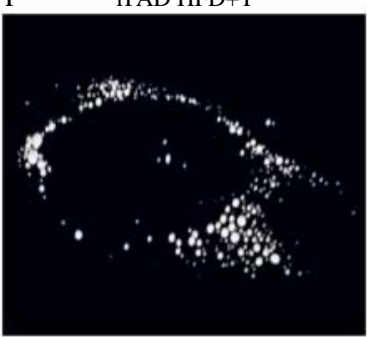

Figure 6 Analysis of the lipid droplet content in DIM-exposed, Adipored-stained rPADs from all rabbit groups. rPADs of RD (A), HFD (B), and testosterone-treated HFD (HFD+T; C) imaged by fluorescence microscopy (magnification 20 X). (G) Adiporedpositive cells were counted using ImageJ software and expressed as percentage change over total cells. rPADs of RD (D), HFD (E), and HFD + T; (F) imaged by confocal microscopy (magnification $63 \times$ ). Images were quantitatively analyzed using Volocity 5 software to measure the number $(\mathrm{H})$ and size $\left(\mu \mathrm{m}^{3} ; \mathrm{I}\right)$ of lipid droplets within the single cell. At least eight cells were analyzed for each group. Results are reported as mean \pm S.E.M. ${ }^{*} P<0 \cdot 05 ;{ }^{* *} P<0 \cdot 01 ;{ }^{* * *} P<0 \cdot 0001 \mathrm{vs} \mathrm{RD} ;{ }^{\circ} P<0 \cdot 01 ;{ }^{\circ \circ} P<0 \cdot 001 ;{ }^{\circ 0 \circ} P<0 \cdot 0001$ vs HFD. Full color version of this figure available via http://dx.doi.org/10.1530/JOE-12-0333.

glucose transport, and insulin signaling. In particular, $A R$ was positively associated with the expression of SYNT5, $S N A P 23$, and $V A M P 4$, which encode for proteins belonging to the SNARE complex, crucially involved in the processes of lipid droplet formation (Boström et al. 2007). Besides the positive association with GLUT4, AR mRNA also correlated with $R H O A, R O C K 2$, and $V I M$, all proteins implicated in the cytoskeleton remodeling required for the insulinstimulated intracellular trafficking of GLUT4 vesicles (Hirata et al. 2011, Chun et al. 2012). Moreover, a highly significant positive correlation was found between $A R$ and STAMP2, whose expression is required for normal insulin signaling, as demonstrated in loss-of-function studies (Wellen et al. 2007). This protein is upregulated by TNF- $\alpha$ and by nutrient stimuli and has been characterized as a counter-regulator of inflammation and insulin resistance in mice (Waki \& Tontonoz 2007, Wellen et al. 2007). Accordingly, STAMP2 gene expression in VAT was significantly decreased in obese subjects, mainly in those with type 2 diabetes, and was associated with adipose tissue dysfunction (Moreno-Navarrete et al. 2011). Interestingly, STAMP2 is induced by androgens in androgen-regulated prostate cells (Korkmaz et al. 2005). Consistent with these findings, we observed a significant increase in STAMP2 mRNA in VAT from testosteronetreated MetS rabbits, thus indicating the occurrence of an androgen-dependent activation of regulatory mechanisms linking inflammatory and nutritional signals with metabolism.

Overall, our data suggest that a direct AR-mediated action of testosterone on VAT function in the MetS model could lead to two different, apparently opposite, biological effects: i) anti-adipogenic, explaining the dramatic inhibitory effect of testosterone dosing on the HFD-induced VAT expansion (tenfold decrease) and ii) pro-adipogenic, as derived from the positive association found between VAT expression of $A R$ and genes involved in lipid turnover. However, the mechanisms through which testosterone exerts these effects in vivo are complex and only in part clarified.

The anti-adipogenic action is in agreement with previous studies in vitro (Singh et al. 2003, 2006, Gupta et al. 2008) and in vivo (ARKO mice), clearly demonstrating the role of 
Table 6 Effect of DIM on mRNA expression of adipocyte-related genes in rPADs. Relative mRNA expression of adipocyte-related genes was evaluated using QRT-PCR in untreated (time 0 ) and DIM-exposed rPADs from RD, HFD, and testosterone-treated HFD. Data were calculated according to comparative $C_{\mathrm{t}}$ method using $18 S$ rRNA subunit as the reference gene for normalization. Results are reported as the mean \pm s.D. of five different experiments, each performed in triplicate using a different cell preparation per group and are expressed in fold change over time 0

RD

Adipocyte-related genes

$\begin{array}{lccc}\text { DKK1 } & 10 \pm 7 \cdot 3^{+} & 1 \cdot 4 \pm 1 \cdot 1^{\ddagger} & 3 \cdot 6 \pm 2^{+} \\ \text {CEBPA } & 2 \pm 0 \cdot 9^{+} & 1 \cdot 2 \pm 0 \cdot 4^{\ddagger} & 2 \cdot 4 \pm 0 \cdot 4^{+} \\ \text {PPARG } & 2 \cdot 3 \pm 1 \cdot 1^{+} & 1 \pm 0 \cdot 7^{\ddagger} & 1 \cdot 8 \pm 0 \cdot 7^{+} \\ \text {FABP4 } & 19 \cdot 2 \pm 12 \cdot 5^{+} & 5 \cdot 2 \pm 3 \cdot 3^{+} & 14 \cdot 3 \pm 8^{+} \\ \text {ADPN } & 12 \cdot 4 \pm 8 \cdot 2^{\dagger} & 0 \cdot 9 \pm 0 \cdot 4^{\ddagger} & 3 \cdot 8 \pm 1 \cdot 5^{+} \\ \text {LEPT } & 8 \cdot 5 \pm 4 \cdot 7^{+\ddagger} & 0 \cdot 6 \pm 0 \cdot 3 & 1 \cdot 1 \pm 1 \cdot 4 \\ \text { CCND1 } & 0 \cdot 9 \pm 0 \cdot 7 & 2 \cdot 3 \pm 1 \cdot 6^{*} & 0 \cdot 3 \pm 0 \cdot 1 \\ \text { CCND3 } & 2 \cdot 5 \pm 1 \cdot 3^{*, \S} & 1 \cdot 3 \pm 0 \cdot 7 & 4 \cdot 8 \pm 2 \cdot 6^{\dagger, \|}\end{array}$

${ }^{*} P<0.05 ;{ }^{+} P<0.01$ vs relative time $0 ;{ }^{\ddagger} P<0.01$ vs all other groups; ${ }^{\S} P<0 \cdot 05 ; " P<0 \cdot 01$ vs relative $C C N D 1$.

androgens in decreasing visceral adiposity (Yanase et al. 2008). Accordingly, we found a negative association between $A R$ and VAT expression of DKK1, which acts as an important inhibitor of Wnt signaling and is normally upregulated during the early steps of adipogenesis (Christodoulides et al. 2009). In addition, both $\Delta \mathrm{T}$ and VAT $A R$ mRNA positively correlated with VAT expression of the proapoptotic gene $B A X$. The promotion of BAX-mediated apoptosis by androgen and its receptor has been already reported in different cellular systems (Lin et al. 2006), but not fully investigated in this study. Whether the induction of apoptotic processes could be an additional mechanism through which testosterone counteracts VAT expansion in MetS rabbits remains to be demonstrated.

Concerning the mechanisms through which testosterone may exert pro-adipogenic effects, our results in isolated $\mathrm{rPAD}$ indicate that an androgen-dependent preservation of insulin sensitivity (and thereby of adipocyte-specific functions) is responsible for restoring normal morphological and functional VAT features. Despite VAT expansion, rPAD from HFD rabbits showed a reduced ability in responding to adipogenic DIM and in particular to insulin, as demonstrated by the reduced ability of triglycerides synthesis, glucose uptake, and GLUT4 membrane localization, as well as by the impaired induction of adipogenesis-specific genes. In rPADs from testosterone-treated HFD rabbits, all the DIM-induced adipocyte functions, including insulin-stimulated GLUT4 membrane translocation, glucose uptake, and triglyceride synthesis, were preserved and comparable to those observed in rPADs from RD rabbits. Our data are in perfect agreement with a recent study in nonhuman primates (Varlamov et al. 2012).

We speculate that the expansion of fat mass in experimental MetS may be ascribed to the lipid overloading, and consequent enlargement, of mature adipocytes, likely dysfunctional, rather than to their replacement with newly synthesized and functional small adipocytes. In this regard, our in vitro results in isolated rPADs are indicative of a defect in preadipocyte maturation, which may impair the correct cell turnover in VAT of MetS rabbits. Accordingly, rPADs from HFD had increased CCND1 expression after DIM induction, while CCND3 remained unchanged. Indeed, it has been reported that $C C N D 1$ blocks adipocyte maturation by antagonizing the function of CEBPA and PPARG and it is specifically induced only during preadipocyte clonal expansion (Fu et al. 2004). By contrast, prevalent expression of $C C N D 3$, as compared with $C C N D 1$, has been reported as a marker of adipogenic differentiation ( $\mathrm{Fu}$ et al. 2004). Moreover, we found that in rPADs from HFD, DIM exposure
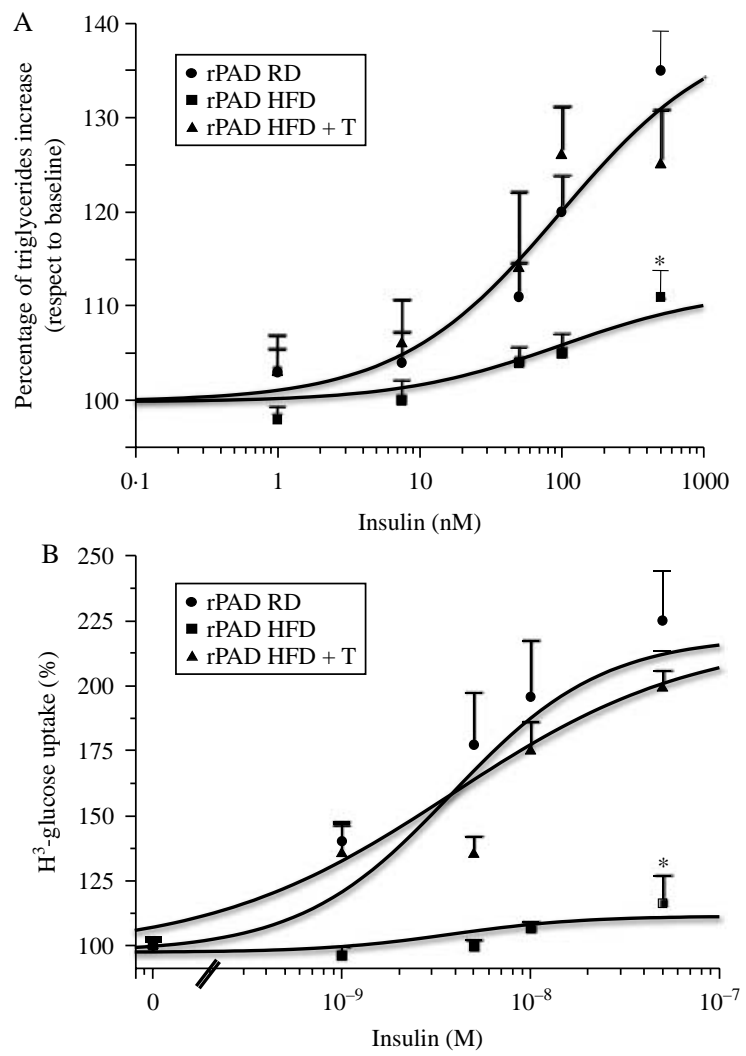

Figure 7 Insulin sensitivity of DIM-exposed rPADs. (A) Doseresponse curves of the lipid synthesis in DIM-treated rPADs after exposure to increasing concentrations of insulin, as evaluated by Adipored assay. Results are expressed in percentage of $0 \mathrm{nM}$ (baseline) insulin and are reported as mean \pm S.E.M. of four different experiments, each performed in triplicate and using a different cell preparation per group. The relative $\mathrm{EC}_{50} \mathrm{~S}$ and $E_{\mathrm{max}}$ values are reported in the text. ${ }^{*} P<0.01$ vs $E_{\max }$ of all other groups. (B) Dose-response curves of radiolabeled $\left(\mathrm{H}^{3}\right)$ glucose uptake in DIM-treated $\mathrm{rPADs}$ after exposure to increasing concentrations of insulin. Results are expressed in percentage over $0 \mathrm{nM}$ insulin and are reported as mean \pm S.E.M. of four different experiments, each performed in duplicate and using a different cell preparation per group. The relative $\mathrm{EC}_{50} \mathrm{~S}$ and $E_{\max }$ values are reported in the text. ${ }^{*} P<0 \cdot 01$ vs $E_{\max }$ of all other groups. 

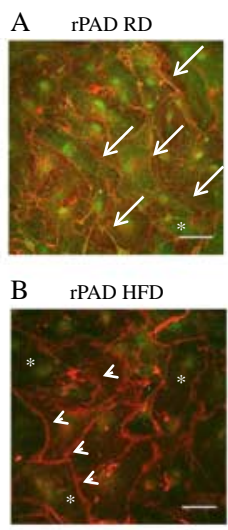

C $\operatorname{rPAD~HFD+T}$

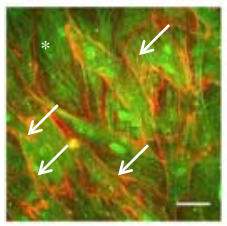

E rPAD RD

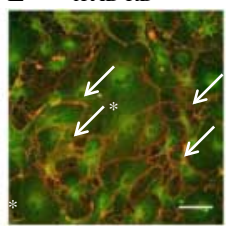

F $\quad$ rPAD HFD

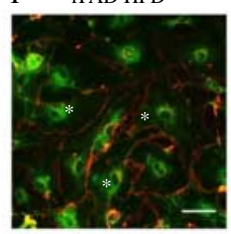

$\mathrm{G} \quad \mathrm{rPAD}$ HFD+T

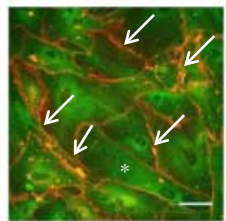

$\mathrm{D}$

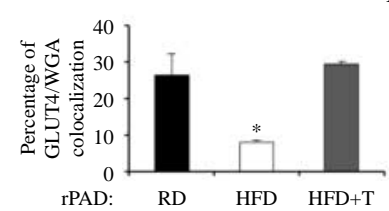

$\mathrm{H}$

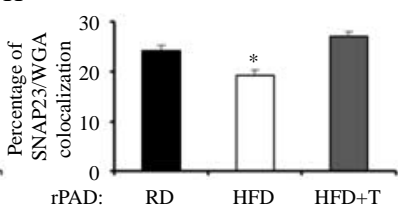

Figure 8 Effect of insulin (100 nM, $5 \mathrm{~min})$ on GLUT4 or SNAP23 membrane immunolocalization in DIM-exposed rPADs of RD (A, E respectively), HFD plus testosterone (HFD) (B, F respectively), and $\mathrm{HFD}+\mathrm{T}$; $\mathrm{C}, \mathrm{G}$, respectively) rabbits. Immunolocalization was displayed by dual labeling of anti-WGA (membrane marker) antibody (red color or white arrowheads) and anti-GLUT4 or antiSNAP23 (green color or white asterisk) antibodies, and colocalization is shown by merging the images (yellow color or white arrows). Percentage of GLUT4/WGA (D) or SNAP23/WGA (H) colocalization was detected with Leica SP2-AOBS confocal microscope and calculated using ImageJ software. Data are reported as mean \pm S.E.M. $(n=3)$. Bars $=58 \mu \mathrm{m} .{ }^{*} P<0.01$ vs the other groups. Full color version of this figure available via http://dx. doi.org/10.1530/JOE-12-0333.

was not able to increase the percentage of Adipored-positive/ differentiating cells, further suggesting that the adipogenic commitment in HFD VAT is impaired. Consistent with the positive effect of testosterone on adipogenesis, rPADs from testosterone-treated MetS rabbits showed a normal induction of CCND3 by DIM, as well as a percentage of DIM-induced Adipored-positive cells comparable with that of RD cells.

An additional sign of insulin resistance in rPADs from HFD rabbits, which was normalized by testosterone treatment, is the altered DIM-induced formation of lipid droplets, as observed with confocal microscopy. In particular, reduced neo-formation (reduced number) and altered fusion processes (increased size) of lipid droplets, along with decreased SNAP23 membrane localization, were observed in rPADs from HFD, compared with rPADs from RD. Among the proteins forming the SNARE complex, SNAP23 has also a key role in the regulation of insulin sensitivity, mediating the fusion of GLUT4 vesicles with the cell membrane (Boström et al. 2007). However, under conditions of dyslipidemia (high intake of fatty acids), SNAP23 is sequestered in the cytosol, where it mainly mediates the fusion of lipid droplets, with the consequent increase of their size. Interestingly, rPADs from testosterone-treated HFD rabbits were characterized by a prominent localization of SNAP23 to the membrane, as well as by lipid droplets that are reduced in size, but increased in number. This finding further demonstrates a testosterone-mediated increase in insulin sensitivity.

Overall, our observations not only reinforce the evidence of a positive effect of testosterone on insulin signaling in adipocytes but also indicates that its action is persistent, as a sort of 'metabolic memory', during in vitro experiments. Hence, the involvement of epigenetic mechanisms could be envisaged and should be properly investigated in future studies.

In conclusion, our study in an experimental model of MetS adds new information about the link between visceral obesity, hypogonadism, and metabolic alterations, all factors strictly associated with a potential CV risk. In particular, our results suggest that MetS rabbits are characterized by an accumulation of a dysfunctional VAT in which the normal differentiation process appears to be compromised because of impaired insulin signaling. The in vivo treatment with testosterone seems to preserve VAT function, through the maintenance of insulin sensitivity, which, in turn, allows preadipocyte commitment and a normal cell turnover. These effects could be seen as protective against the hypertrophic expansion of VAT that becomes dysfunctional, leading to the deleterious metabolic consequences typical of MetS.

\section{Declaration of interest}

E M, A M, S F, I C, B M, P C, T M, A C, E S, L V, R V, and G B V have nothing to declare. F $S$ is an employee of Bayer Pharma AG, Berlin, Germany. M $M$ is a scientific consultant for Bayer Pharma AG, Germany, Eli-Lilly Indianapolis, Indiana; Intercept Pharmaceuticals Italia Perugia, Italy.

\section{Funding}

The work was supported by PRIN (Programmi di ricerca di Rilevante Interesse Nazionale, protocol no. 20099BXMJH 002) and FIRB (Fondo per gli investimenti alla ricerca di base, protocol no. 2010RBFR10VJ56 002), both funds from the Italian Minister of University, Research and Instruction and by Under40-Young Investigators funds from the Italian Minister of Health (grant no. GR2008-1137632).

\section{Acknowledgements}

The authors would like to thank Susanna Benvenuti (Department of Clinical Physiopathology, University of Florence) for her help in isolation and culture of preadipocytes. 


\section{References}

Aguiari P, Leo S, Zavan B, Vindigni V, Rimessi A, Bianchi K, Franzin C, Cortivo R, Rossato M, Vettor R et al. 2008 High glucose induces adipogenic differentiation of muscle-derived stem cells. PNAS $\mathbf{1 0 5}$ 1226-1231. (doi:10.1073/pnas.0711402105)

Boström P, Andersson L, Rutberg M, Perman J, Lidberg U, Johansson BR, Fernandez-Rodriguez J, Ericson J, Nilsson T, Borén J et al. 2007 SNARE proteins mediate fusion between cytosolic lipid droplets and are implicated in insulin sensitivity. Nature Cell Biology 9 1286-1293. (doi:10.1038/ ncb1648)

Brasaemle DL 2007 Thematic review series: adipocyte biology. The perilipin family of structural lipid droplet proteins: stabilization of lipid droplets and control of lipolysis. Journal of Lipid Research 48 2547-2559. (doi:10.1194/ jlr.R700014-JLR200)

Christodoulides C, Laudes M, Cawthorn WP, Schinner S, Soos M, O'Rahilly S, Sethi JK \& Vidal-Puig A 2006 The Wnt antagonist Dickkopf-1 and its receptors are coordinately regulated during early human adipogenesis. Journal of Cell Science 119 2613-2620. (doi:10.1242/jcs.02975)

Christodoulides C, Lagathu C, Sethi JK \& Vidal-Puig A 2009 Adipogenesis and WNT signalling. Trends in Endocrinology and Metabolism 20 16-24. (doi:10.1016/j.tem.2008.09.002)

Chun KH, Araki K, Jee Y, Lee DH, Oh BC, Huang H, Park KS, Lee SW, Zabolotny JM \& Kim YB 2012 Regulation of glucose transport by ROCK1 differs from that of ROCK2 and is controlled by actin polymerization. Endocrinology 153 1649-1662. (doi:10.1210/ en.2011-1036)

Corona G, Mannucci E, Schulman C, Petrone L, Mansani R, Cilotti A, Balercia G, Chiarini V, Forti G \& Maggi M 2006 Psychobiologic correlates of the metabolic syndrome and associated sexual dysfunction. European Urology 50 595-604. (doi:10.1016/j.eururo.2006.02.053)

Corona G, Mannucci E, Forti G \& Maggi M 2009 Hypogonadism, ED, metabolic syndrome and obesity: a pathological link supporting cardiovascular diseases. International Journal of Andrology 32 587-598. (doi:10.1111/j.1365-2605.2008.00951.x)

Corona G, Monami M, Rastrelli G, Aversa A, Tishova Y, Saad F, Lenzi A, Forti G, Mannucci E \& Maggi M 2011a Testosterone and metabolic syndrome: a meta-analysis study. Journal of Sexual Medicine 8 272-283. (doi:10.1111/j.1743-6109.2010.01991.x)

Corona G, Monami M, Rastrelli G, Melani C, Balzi D, Sforza A, Forti G, Mannucci E \& Maggi M $2011 b$ Is metabolic syndrome a useless category in subjects with high cardiovascular risk? Results from a cohort study in men with erectile dysfunction Journal of Sexual Medicine 8 504-511. (doi:10.1111/j.1743-6109.2010.02126.x)

De Lean A, Munson PJ \& Rodbard D 1978 Simultaneous analysis of families of sigmoidal curves: applications to bioassay, radioligand assay, and physiological dose-response curves. American Journal of Physiology 235 97-102.

Després JP \& Lemieux I 2006 Abdominal obesity and metabolic syndrome. Nature 444 881-887. (doi:10.1038/nature05488)

Esposito K, Giugliano F, Ciotola M, De Sio M, D'Armiento M \& Giugliano D 2008 Obesity and sexual dysfunction, male and female. International Journal of Impotence Research 20 358-365. (doi:10.1038/ ijir.2008.9)

Fan W, Yanase T, Nomura M, Okabe T, Goto K, Sato T, Kawano H, Kato S \& Nawata H 2005 Androgen receptor null male mice develop late-onset obesity caused by decreased energy expenditure and lipolytic activity but show normal insulin sensitivity with high adiponectin secretion. Diabetes 54 1000-1008. (doi:10.2337/diabetes.54.4.1000)

Filippi S, Vignozzi L, Morelli A, Chavalmane AK, Sarchielli E, Fibbi B, Saad F, Sandner P, Ruggiano P, Vannelli GB et al. 2009 Testosterone partially ameliorates metabolic profile and erectile responsiveness to PDE5 inhibitors in an animal model of male metabolic syndrome. Journal of Sexual Medicine 6 3274-3288. (doi:10.1111/j.1743-6109.2009.01467.x)

Fu M, Wang C, Li Z, Sakamaki T \& Pestell RG 2004 Minireview: cyclin D1: normal and abnormal functions. Endocrinology 145 5439-5447. (doi:10.1210/en.2004-0959)
Gupta V, Bhasin S, Guo W, Singh R, Miki R, Chauhan P, Choong K, Tchkonia T, Lebrasseur NK, Flanagan JN et al. 2008 Effects of dihydrotestosterone on differentiation and proliferation of human mesenchymal stem cells and preadipocytes. Molecular and Cellular Endocrinology 296 32-40. (doi:10.1016/j.mce.2008.08.019)

Halvorsen YD, Bond A, Sen A, Franklin DM, Lea-Currie YR, Sujkowski D, Ellis PN, Wilkison WO \& Gimble JM 2001 Thiazolidinediones and glucocorticoids synergistically induce differentiation of human adipose tissue stromal cells: biochemical, cellular, and molecular analysis. Metabolism 50 407-413. (doi:10.1053/meta.2001.21690)

Hirata Y, Hosaka T, Iwata T, Le CT, Jambaldorj B, Teshigawara K, Harada N, Sakaue H, Sakai T, Yoshimoto K et al. 2011 Vimentin binds IRAP and is involved in GLUT4 vesicle trafficking. Biochemical and Biophysical Research Communications 405 96-101. (doi:10.1016/j.bbrc.2010.12.134)

Hishida T, Naito K, Osada S, Nishizuka M \& Imagawa M 2008 Crucial roles of D-type cyclins in the early stage of adipocyte differentiation. Biochemical and Biophysical Research Communications 370 289-294. (doi:10.1016/j.bbrc. 2008.03.091)

Hosogai N, Fukuhara A, Oshima K, Miyata Y, Tanaka S, Segawa K, Furukawa S, Tochino Y, Komuro R, Matsuda M et al. 2007 Adipose tissue hypoxia in obesity and its impact on adipocytokine dysregulation. Diabetes 56 901-911. (doi:10.2337/db06-0911)

Huang S \& Czech MP 2007 The GLUT4 glucose transporter. Cell Metabolism 5 237-252. (doi:10.1016/j.cmet.2007.03.006)

Jacobsson B \& Smith U 1972 Effect of cell size on lipolysis and antilipolytic action of insulin in human fat cells. Journal of Lipid Research 13 651-656.

Kapoor D, Malkin CJ, Channer KS \& Jones TH 2005 Androgens, insulin resistance and vascular disease in men. Clinical Endocrinology 63 239-250. (doi:10.1111/j.1365-2265.2005.02299.x)

Korkmaz CG, Korkmaz KS, Kurys P, Elbi C, Wang L, Klokk TI, Hammarstrom C, Troen G, Svindland A, Hager GL et al. 2005 Molecular cloning and characterization of STAMP2, an androgen-regulated six transmembrane protein that is overexpressed in prostate cancer. Oncogene 24 4934-4945. (doi:10.1038/sj.onc.1208677)

Kupelian V, Page ST, Araujo AB, Travison TG, Bremner WJ \& McKinlay JB 2006 Low sex hormone-binding globulin, total testosterone, and symptomatic androgen deficiency are associated with development of the metabolic syndrome in nonobese men. Journal of Clinical Endocrinology and Metabolism 91 843-850. (doi:10.1210/jc.2005-1326)

Laaksonen DE, Niskanen L, Punnonen K, Nyyssönen K, Tuomainen TP, Salonen R, Rauramaa R \& Salonen JT 2003 Sex hormones, inflammation and the metabolic syndrome: a population-based study. European Journal of Endocrinology 149 601-608. (doi:10.1530/eje.0.1490601)

Lin HY, Xu Q, Yeh S, Wang RS, Sparks JD \& Chang C 2005 Insulin and leptin resistance with hyperleptinemia in mice lacking androgen receptor. Diabetes 54 1717-1725. (doi:10.2337/diabetes.54.6.1717)

Lin Y, Kokontis J, Tang F, Godfrey B, Liao S, Lin A, Chen Y \& Xiang J 2006 Androgen and its receptor promote Bax-mediated apoptosis. Molecular and Cellular Biology 26 1908-1916. (doi:10.1128/MCB.26.5.1908-1916.2006)

Mazzanti B, Aldinucci A, Biagioli T, Barilaro A, Urbani S, Dal Pozzo S, Amato MP, Siracusa G, Crescioli C, Manuelli C et al. 2008 Differences in mesenchymal stem cell cytokine profiles between MS patients and healthy donors: implication for assessment of disease activity and treatment. Journal of Neuroimmunology 199 142-150. (doi:10.1016/j.jneuroim.2008. 05.006)

Morelli A, Comeglio P, Filippi S, Sarchielli E, Vignozzi L, Maneschi E, Cellai I, Gacci M, Lenzi A, Vannelli GB et al. 2012a Mechanism of action of phosphodiesterase type 5 inhibition in metabolic syndrome-associated prostate alterations: an experimental study in the rabbit. Prostate. In press. (doi:10.1002/pros.22584)

Morelli A, Comeglio P, Filippi S, Sarchielli E, Cellai I, Vignozzi L, Yehiely-Cohen R, Maneschi E, Gacci M, Carini M et al. 2012b Testosterone and farnesoid X receptor agonist INT-747 counteract high fat diet-induced bladder alterations in a rabbit model of metabolic syndrome. Journal of Steroid Biochemistry and Molecular Biology 132 80-92. (doi:10.1016/ j.jsbmb.2012.02.007)

Moreno-Navarrete JM, Ortega F, Serrano M, Pérez-Pérez R, Sabater M, Ricart W, Tinahones F, Peral B \& Fernández-Real JM 2011 Decreased 
STAMP2 expression in association with visceral adipose tissue dysfunction. Journal of Clinical Endocrinology and Metabolism 96 1816-1825. (doi:10.1210/ jc.2011-0310)

Niskanen L, Laaksonen DE, Punnonen K, Mustajoki P, Kaukua J \& Rissanen A 2004 Changes in sex hormone-binding globulin and testosterone during weight loss and weight maintenance in abdominally obese men with the metabolic syndrome. Diabetes, Obesity \& Metabolism 6 208-215. (doi:10.1111/j.1462-8902.2004.00335.x)

Oh JY, Barrett-Connor E, Wedick NM, Wingard DL \& Rancho Bernardo Study 2002 Endogenous sex hormones and the development of type 2 diabetes in older men and women: the Rancho Bernardo study. Diabetes Care 25 55-60. (doi:10.2337/diacare.25.1.55)

Olefsky JM 1976 The effects of spontaneous obesity on insulin binding, glucose transport, and glucose oxidation of isolated rat adipocytes. Journal of Clinical Investigation 57 842-851. (doi:10.1172/JCI108360)

O'Rourke RW, White AE, Metcalf MD, Olivas AS, Mitra P, Larison WG Cheang EC, Varlamov O, Corless CL, Roberts CT Jr et al. 2011 Hypoxia-induced inflammatory cytokine secretion in human adipose tissue stromovascular cells. Diabetologia 54 1480-1490. (doi:10.1007/s00125011-2103-y)

Quarta C, Bellocchio L, Mancini G, Mazza R, Cervino C, Braulke LJ, Fekete C, Latorre R, Nanni C, Bucci M et al. 2010 CB(1) signaling in forebrain and sympathetic neurons is a key determinant of endocannabinoid actions on energy balance. Cell Metabolism 11 273-285. (doi:10.1016/ j.cmet.2010.02.015)

Raimondi L, De Paoli P, Mannucci E, Lonardo G, Sartiani L, Banchelli G, Pirisino R, Mugelli A \& Cerbai E 2004 Restoration of cardiomyocyte functional properties by angiotensin II receptor blockade in diabetic rats. Diabetes 53 1927-1933. (doi:10.2337/diabetes.53.7.1927)

Rosano GM, Sheiban I, Massaro R, Pagnotta P, Marazzi G, Vitale C, Mercuro G, Volterrani M, Aversa A \& Fini M 2007 Low testosterone levels are associated with coronary artery disease in male patients with angina. International Journal of Impotence Research 19 176-182. (doi:10.1038/sj.ijir. 3901504)

Rosen ED \& MacDougald OA 2006 Adipocyte differentiation from the inside out. Nature Reviews. Molecular Cell Biology 7 885-896. (doi:10.1038/ nrm2066)

Salans LB \& Dougherty JW 1971 The effect of insulin upon glucose metabolism by adipose cells of different size. Influence of cell lipid and protein content, age, and nutritional state. Journal of Clinical Investigation $\mathbf{5 0}$ 1399-1410. (doi:10.1172/JCI106623)

Sato T, Matsumoto T, Yamada T, Watanabe T, Kawano H \& Kato S 2003 Late onset of obesity in male androgen receptor-deficient (AR KO) mice. Biochemical and Biophysical Research Communications 300 167-171. (doi:10.1016/S0006-291X(02)02774-2)

Singh R, Artaza JN, Taylor WE, Gonzalez-Cadavid NF \& Bhasin S 2003 Androgens stimulate myogenic differentiation and inhibit adipogenesis in C3H 10T1/2 pluripotent cells through an androgen receptor-mediated pathway. Endocrinology 144 5081-5088. (doi:10.1210/en.2003-0741)

Singh R, Artaza JN, Taylor WE, Braga M, Yuan X, Gonzalez-Cadavid NF \& Bhasin S 2006 Testosterone inhibits adipogenic differentiation in 3T3-L1 cells: nuclear translocation of androgen receptor complex with $\beta$-catenin and T-cell factor 4 may bypass canonical Wnt signaling to down-regulate adipogenic transcription factors. Endocrinology 147 141-154. (doi:10.1210/ en.2004-1649)

Smith U 1971 Effect of cell size on lipid synthesis by human adipose tissue in vitro. Journal of Lipid Research 12 65-70.

Stellato RK, Feldman HA, Hamdy O, Horton ES \& McKinlay JB 2000 Testosterone, sex hormone-binding globulin, and the development of type 2 diabetes in middle-aged men: prospective results from the Massachusetts male aging study. Diabetes Care 23 490-494. (doi:10.2337/ diacare.23.4.490)

Student AK, Hsu RY \& Lane MD 1980 Induction of fatty acid synthetase synthesis in differentiating 3T3-L1 preadipocytes. Journal of Biological Chemistry 255 4745-4750.

Trayhurn P, Wang B \& Wood IS 2008 Hypoxia in adipose tissue: a basis for the dysregulation of tissue function in obesity? British Journal of Nutrition $\mathbf{1 0 0}$ 227-235. (doi:10.1017/S0007114508971282)

Varlamov O, White AE, Carroll JM, Bethea CL, Reddy A, Slayden O, O'Rourke RW \& Roberts CT Jr 2012 Androgen effects on adipose tissue architecture and function in nonhuman primates. Endocrinology $\mathbf{1 5 3}$ 3100-3110. (doi:10.1210/en.2011-2111)

Vettor R, Milan G, Rossato M \& Federspil G 2005 Review article: adipocytokines and insulin resistance. Alimentary Pharmacology $\mathcal{E}$ Therapeutics 2 3-10. (doi:10.1111/j.1365-2036.2005.02587.x)

Vettor R, Milan G, Franzin C, Sanna M, De Coppi P, Rizzuto R \& Federspil G 2009 The origin of intermuscular adipose tissue and its pathophysiological implications. American Journal of Physiology. Endocrinology and Metabolism 297 E987-E998. (doi:10.1152/ajpendo.00229.2009)

Vignozzi L, Morelli A, Filippi S, Comeglio P, Chavalmane AK, Marchetta M, Toce M, Yehiely-Cohen R, Vannelli GB, Adorini L et al. 2011 Farnesoid X receptor activation improves erectile function in animal models of metabolic syndrome and diabetes. Journal of Sexual Medicine 8 57-77. (doi:10.1111/j.1743-6109.2010.02073.x)

Vignozzi L, Morelli A, Sarchielli E, Comeglio P, Filippi S, Cellai I, Maneschi E, Serni S, Gacci M, Carini M et al. 2012 Testosterone protects from metabolic syndrome-associated prostate inflammation: an experimental study in rabbit. Journal of Endocrinology 212 71-84. (doi:10.1530/ JOE-11-0289)

Virtue S \& Vidal-Puig A 2010 Adipose tissue expandability, lipotoxicity and the metabolic syndrome - an allostatic perspective. Biochimica et Biophysica Acta 1801 338-349. (doi:10.1016/j.bbalip.2009.12.006)

Waki H \& Tontonoz P 2007 STAMPing out Inflammation. Cell 129 451-452. (doi:10.1016/j.cell.2007.04.022)

Wellen KE, Fucho R, Gregor MF, Furuhashi M, Morgan C, Lindstad T, Vaillancourt E, Gorgun CZ, Saatcioglu F \& Hotamisligil GS 2007 Coordinated regulation of nutrient and inflammatory responses by STAMP2 is essential for metabolic homeostasis. Cell 129 537-548. (doi:10.1016/j.cell.2007.02.049)

Yanase T, Fan W, Kyoya K, Min L, Takayanagi R, Kato S \& Nawata H 2008 Androgens and metabolic syndrome: lessons from androgen receptor knock out (ARKO) mice. Journal of Steroid Biochemistry and Molecular Biology 109 254-257. (doi:10.1016/j.jsbmb.2008.03.017)

Ye J, Gao Z, Yin J \& He Q 2007 Hypoxia is a potential risk factor for chronic inflammation and adiponectin reduction in adipose tissue of ob/ob and dietary obese mice. American Journal of Physiology. Endocrinology and Metabolism 293 1118-1128. (doi:10.1152/ajpendo.00435.2007)

Zuk PA, Zhu M, Mizuno H, Huang J, Futrell JW, Katz AJ, Benhaim P, Lorenz HP \& Hedrick MH 2001 Multilineage cells from human adipose tissue: implications for cell-based therapies. Tissue Engineering 7 211-228. (doi:10.1089/107632701300062859)

Received in final form 14 September 2012

Accepted 8 October 2012

Made available online as an Accepted Preprint 8 October 2012 